\title{
ARTÍ́CULOS
}

\section{LA EUROPEIZACIÓN DE GRECIA Y LOS ANTECEDENTES DE SU TEMPRANO ACCESO A LA EUROPA COMUNITARIA}

\author{
Ana I. Sanz-Yagüe \\ U.N.E.D. \\ anaisy@telefonica.net
}

Recibido: 20/04/2016 - Aceptado: 14/09/2016

\author{
Cómo citar este artículo/Citation: \\ Ana I. SANZ YAGÜE, (2017), "La europeización de Grecia y los \\ antecedentes de su temprano acceso a la Europa \\ comunitaria", Hispania Nova, 15, págs. 217 a 242. \\ DOI: https://doi.org/10.20318/hn.2017.3487
}

\section{The Europeanization of Greece and the Background of Its Early Access to the European Communities}

Copyright: C HISPANIA NOVA es una revista debidamente
registrada, con ISSN $1138-7319$ y Depósito Legal M 9472-1998.
Los textos publicados en esta revista están -si no se indica lo
contrario- bajo una licencia Reconocimiento-Sin obras derivadas
$\underline{3.0}$ España de Creative Commons. Puede copiarlos, distribuirlos
y comunicarlos públicamente siempre que cite su autor y la
revista y la institución que los publica y no haga con ellos obras
derivadas. La licencia completa se puede consultar en:
http://creativecommons.org/licenses/by-nd/3.0/es/deed.es

\begin{abstract}
Resumen: La historia contemporánea de Grecia permite distinguir entre una vinculación temprana del país al proceso de integración de Europa, al inicio de la segunda posguerra mundial, y una europeización más tardía, a partir de 1975, cuando comienza a tramitarse su adhesión a las Comunidades Europeas. El artículo aborda estas dos cuestiones desde una perspectiva histórica, así como el impacto del proceso de europeización sobre las estructuras y la dinámica del sistema político griego. La pertenencia a la UE ha significado para Grecia un verdadero apoyo para la democratización y modernización del país. Aquí, la europeización propiamente dicha, aunque pretendida, ha sido más tardía de lo que cabía esperar, y ha suscitado en un principio resistencias. Sin embargo, conforme avanzaban los años noventa, ha habido verdaderamente cambios significativos al respecto.
\end{abstract}

Palabras clave: Grecia, integración europea, europeización, Unión Europea, política exterior.
Abstract: Greece's recent political history makes it possible to distinguish between the country's engagement with the European integration process, soon after the Second World War, and its Europeanization itself, since 1975, when Greece applied to join the European Community. This article addresses both issues from a historical perspective. It also evaluates the impact of Europeanization in the structure and procedures of the Greek political system. For Greece, EU membership has been seen, from the beginning, as a means of encouraging democratization in the country, as well as an external stimulus for advancing modernization. Here Europeanization refers precisely to an intended yet belated process. However, despite initial resistance, EU-influenced domestic changes have become increasingly significant since the mid-1990s.

Keywords: Greece, European integration, Europeanization, European Union, foreign policy 


\section{LA EUROPEIZACIÓN DE GRECIA Y LOS ANTECEDENTES DE SU TEMPRANO ACCESO A LA EUROPA COMUNITARIA}

La reciente crisis de deuda soberana ha acentuado la imagen negativa con que, desde hace tiempo, se ha revestido a Grecia en el seno de la Unión Europea (en adelante, UE). «Los clichés que oponen los "griegos perezosos" a los "austeros alemanes"» tergiversan hechos tan relevantes como la confrontación a que da lugar la confluencia de diversos sistemas de crecimiento en la zona euro ${ }^{1}$. Asimismo, quienes han comparado los Estados miembros en lo que concierne a cuestiones controvertidas -compromisos realizados, incumplimientos, ayudas y cuantía presupuestaria percibidas, etc. - no han hallado una justificación convincente para un marchamo tan peyorativo como el que se atribuye al país heleno ${ }^{2}$, aunque se puedan reprobar, entre otras cuestiones, tanto asuntos relativos a su gobernanza interna como la reincidencia en sus deficientes resultados económicos. Al mismo tiempo, conviene también advertir la ofuscación desde la que se percibe a menudo la dinámica comunitaria, así como los procesos de europeización de sus Estados miembros. Los convencionalismos empañan la realidad ya de por sí difícil de interpretar. En concreto, una realidad compleja, enfrentada al reto de integrar un continente diverso y desigual, el cual empezó a diseñar su unificación, ya de manera inexorable, al finalizar la Segunda Guerra Mundial.

No hay que identificar este último hecho -esto es, la integración - con lo que hoy se entiende por «europeización» en sus diversas acepciones ${ }^{3}$, pero su condición fundamental y primigenia merece

\footnotetext{
${ }^{1}$ Wolfgang STREECK, «Una hegemonía fortuita», Le Monde Diplomatique, no 235 (mayo 2015), pp. 19 y 22.

${ }^{2}$ Kevin FEATHERSTONE, "Introduction», en Kevin FEATHERSTONE y Kostas IFANTIS (eds.), Europe in change. Greece in a changing Europe. Between European integration and Balkan disintegration?, Manchester, Manchester University Press, 1996, pp. 3-16 (pp. 4-9).

${ }^{3}$ Robert LADRECH, «Europeanization of domestic politics and institutions: The case of France», Journal of Common Market Studies, 32 (1994), pp. 69-88; Europeanization and National Politics, Basingstoke, Palgrave Macmillan, 2010; Kevin FEATHERSTONE y George KAZAMIAS «Introduction: Southern Europe and the Process of "Europeanization"», en Kevin Featherstone y George Kazamias (eds.), Europeanization and the Southern Periphery, London, Frank Cass, 2001, pp. 1-22; Maria Green COWLES, James CAPORASO y Tomas RISSE (eds.), Transforming Europe: Europeanization and Domestic Change, Ithaca, NY, Cornell University Press, 2001; Kevin FEATHERSTONE y Claudio M. RADAELLI (eds.), The Politics of Europeanization, New York, Oxford University Press, 2003; Tanja A. Börzel, "Europeanization: How the European Union Interacts with its Member States», en Simon BULMER y Christian LEQUESNE (eds.), The Member States of the European Union, Oxford, Oxford University Press, 2005; «Europeanization: The Domestic Impact of European Union Politics», en Knud Erik JØRGENSEN, Mark A. POLLACK y Ben ROSAMOND (eds.), Handbook of European Union Politics, Londres, Sage, 2007; Gerard DELANTY y Chris RUMFORD, Rethinking Europe: Social Theory and the Implications of Europeanization, Londres/Nueva York,
} 
aquí un tratamiento preliminar y sustantivo, toda vez que, en lo que respecta a Grecia, y de cara a entender su particular problemática, constituye una base sobre la que arraiga parte de la transformación contemporánea del país. De este modo, el primer objetivo de este artículo va a estar orientado a analizar, en todo su recorrido histórico, la vinculación temprana de Grecia al ambicioso proyecto que, como se ha dicho, trató de unificar Europa desde el inicio mismo de la segunda posguerra mundial. Después, se valorará, a grandes rasgos, su europeización propiamente dicha, sin duda más tardía. El concepto dado por Claudio M. Radaelli a esta última expresión, basado, como el de Robert Ladrech, en la idea de proceso, o de proceso de cambio (a veces la europeización también se plantea como resultado), puede servir aquí de referencia, por cuanto es uno de más completos y que más consenso ha obtenido hasta el momento ${ }^{4}$. Si bien aquí no son desechables las definiciones dadas por Robert Ladrech ${ }^{5}$ y Panayiotis C. Ioakimidis ${ }^{6}$, ni ha de olvidarse, en puridad, el referente nuclear de valores y principios europeos sobre el que gravita cualquier proceso concebido como europeización, y al que también quedan sometidas las propias instituciones supranacionales de la $\mathrm{UE}^{7}$.

Generalmente, el proceso de europeización experimentado de manera específica en el seno de los Estados miembros de la UE es mucho más desconocido que la trayectoria y la problemática de las precitadas instituciones supranacionales. Como tema de estudio, apenas comenzó a examinarse hace poco más de un par de décadas, pero su valoración es hoy inexcusable de cara a comprender con un

Routledge, 2005; Heather GRABBE, The EU's transformative power: Europeanization through conditionality in Central and Eastern Europe, Basingstoke/Nueva York, Palgrave Macmillan, 2006; Paolo GRAZIANO y Maarten P. VINK (eds.), Europeanization: New Research Agendas, Basingstoke, Palgrave, 2008; Theofanis EXADAKTYLOS y Claudio M. RADAELLI (ed.), Research Design in European Studies: Establishing Causality in Europeanization, Basingstoke/New York, Plagrave Macmillan, 2012; Nicolás MARISCAL, "Repensando la europeización», Cuadernos Europeos de Deusto, 49 (2013), pp. 19-46.

${ }^{4}$ El concepto de «europeización» dado por Claudio M. Radaelli comprende «los procesos de construcción, difusión e institucionalización de las reglas, tanto formales como informales, de los procedimientos, los paradigmas políticos, los estilos y la "manera de hacer las cosas", así como de las creencias compartidas y las normas, que, una vez definidas y consolidadas en la esfera política de la Unión Europea, pasan a incorporarse, en el ámbito interno de los Estados, a la lógica de los discursos, las identidades, las estructuras políticas y las políticas públicas». Con respecto a la noción de Robert Ladrech, explicitada en la nota siguiente, el planteamiento de Claudio M. Radaelli introduce, con especial énfasis, aspectos como la identidad y la dimensión cognitiva de la política. Cf. Claudio M. Radaelli, «The Europeanization of Public Policy», en Kevin Featherstone y Claudio M. Radaelli (eds.), The Politics..., op. cit., pp. 27-56 (p. 30).

${ }^{5}$ A Robert Ladrech le debemos la originalidad de concebir la europeización como un proceso, concretamente un «proceso en auge capaz de reorientar la dirección y la configuración de las políticas, en la medida en que las dinámicas económicas y políticas de la Comunidad Europea [hoy Unión] pasan a formar parte de la lógica organizativa de las políticas nacionales, de su conformación y ejecución». Nos resulta aquí de gran interés su alusión al aspecto organizacional, aun cuando este es el elemento más discutido por Claudio M. Radaelli, para él ensombrecedor del papel de los individuos en este proceso. Robert LADRECH, "Europeanization of...», op. cit., p. 69. Sobre la crítica de Radaelli, cf. Claudio M. Radaelli, «The Europeanization...”, op. cit., p. 30.

${ }^{6}$ En términos de Panayiotis C. loakimidis, la europeización consistiría en la absorción o «la interiorización de la lógica, las normativas y las dinámicas internas de la UE en el proceso de formulación de las políticas nacionales», lo que comporta «la disposición y la capacidad de los Gobiernos para definir y ejecutar las políticas nacionales sin vulnerar el marco de objetivos de la UE». Panayiotis C. IOAKIMIDIS, "Contradictions between policy and performance», en Kevin FEATHERSTONE y Kostas IFANTIS (eds.), Europe in change..., op. cit., pp. $33-52$ (p. 33).

${ }^{7}$ Cf. al respecto, por ejemplo: Charalambos TSARDANIDIS y Stelios STAVRIDIS, «Greece. From special case to limited Europeanization», en Reuben Wong y Christopher Hill (eds.), National and European Foreign Policies. Towards Europeanization, Londres/Nueva York, Routledge, 2011, pp. 111-130.

HISPANIA NOVA., 15 (2017) -págs. 217-242 DOI: https://doi.org/10.20318/hn.2017.3487 
mínimo rigor la situación contemporánea de cada país, así como su especificidad en la manera de proceder y en su actitud dialógica en el marco comunitario. Asimismo, sería bueno que, por la reciprocidad o, más bien, la idea de intercambio asimétrico que sugiere de manera implícita el concepto, así como por la corresponsabilidad que denota, su reflexión contribuyera a superar el prejuicio aún vigente de concebir a los Estados en clave esencialmente nacional, lo que ayudaría además a desvanecer «la falsa apariencia de que los comportamientos divergentes entre unos países que son más virtuosos que otros son el resultado de la idiosincrasia propia de dichos países y no del contexto institucional en el que se ven obligados a gestionar sus políticas macro» ${ }^{8}$.

En una misma línea, Sarantis E. G. Lolos ha advertido sobre la necesidad de interpretar las decisiones políticas desde una compleja combinación de factores, en la que, sin minusvalorar las características nacionales que parcialmente las condicionan (entre ellas, todo un legado histórico que incluye tradiciones, valores y actitudes, junto a una específica realidad institucional), no deberían nunca soslayarse ni el dominio directo en el que intervienen los Ejecutivos ni la inquebrantable influencia de los condicionantes internacionales, factor este último tanto o más decisivo que los anteriores, por más que se subestime a menudo 9 .

Así, la comprensión de la problemática griega en su relación con la UE, aspecto condicionado irremediablemente hoy (y en lo sucesivo) por la grave crisis económica -a la cual se ha añadido además la de los refugiados, un asunto distinto, pero en absoluto baladí, que afecta a Grecia con la intensidad que cabe esperar de su condición de Estado fronterizo de África y Oriente Próximo-, requiere una valoración amplia, en términos históricos, del proceso de europeización. Entendido, conviene reiterarlo, como un fenómeno cuanto menos bilateral, esencialmente con dos horizontes de referencia interconectados: por una parte, el ámbito supranacional de la UE; por otra, el del Estado, su estratificación política y su ciudadanía, donde, de manera en absoluto uniforme, se perciben el impacto, directo e indirecto, y las acciones intrínsecamente vinculadas de un modo $u$ otro a lo que acontece en la esfera comunitaria. Una dialéctica que comenzó a gestarse, en este caso concreto, en fechas muy tempranas, aunque su progresión haya sido irregular. En efecto, desde los años sesenta, Grecia ha representado el primer gran reto de convergencia europeo y uno de los más complejos, por cuanto el acercamiento entre las partes concernientes - por un lado, el núcleo de Estados ya integrados; por otro, el país heleno- debía superar un elevado margen de desigualdad. Una brecha de partida que ha de contextualizarse en un amplio marco internacional.

Para Kevin Featherstone y Kostas Ifantis, en una avanzada segunda mitad del siglo XX, la política exterior griega experimentó una notable transición en la que se vio obligada a responder a presiones de cierta entidad procedentes de tres ámbitos fundamentales: los Balcanes, la Unión Europea y el sistema internacional posterior al fin de la Guerra $\mathrm{Frí}^{10}$, con la atención puesta aquí en las relaciones con

\footnotetext{
${ }^{8}$ Manuel SANCHIS I MARCO, El fracaso de las élites. Lecciones y escarmientos de la gran crisis, Barcelona, Pasado y Presente, 2014, p. 208.

${ }^{9}$ Sarantis E. G. LOLOS, «The role of European Integration in the reform process: the Greek experience», en Mats LUNDAHL y Michael L. WYZAN (eds.), The Political Economy of Reform Failure, Nueva York, Routledge, 2005, pp. 70-88 (p. 71).

${ }^{10}$ Kevin FEATHERSTONE y Kostas IFANTIS (eds.), Europe in change..., op. cit. Cf. asimismo: Kevin FEATHERSTONE y Dimitrios K. KATSOUDAS (eds.), Political Change in Greece: Before and After the Colonels, London/Sydney, Croom Helm, 1987; Panayiotis. IOAKIMIDIS, «The Europeanisation of Greece's Foreign Policy: Progress and Problems», en
} 
Turquía en torno al problema del Egeo y la cuestión chipriota ${ }^{11}$. En el inicio mismo de la segunda posguerra mundial que valoraremos a continuación los parámetros apenas difieren, aunque la integración europea, como la Guerra Fría, fueran todavía fenómenos incipientes.

\section{EN LA ÓRBITA dE LA GUERRA FRÍA}

Grecia no logró pacificarse al finalizar la Segunda Guerra Mundial, tras la capitulación de la Alemania nazi, el 8 de mayo de 1945. Por contra, se enzarzó pronto en una guerra civil que, durante un trienio (de octubre de 1946 a octubre de 1949), representó su último episodio de violencia intestina, al que habían precedido otros de forma discontinua durante los años previos de resistencia a la triple ocupación del país por parte de Italia, Alemania y Bulgaria y de posterior liberación ${ }^{12}$. El 31 de marzo de 1946, los griegos celebraron unas conflictivas elecciones parlamentarias bajo la supervisión de Francia, Gran Bretaña y Estados Unidos - la Allied Mission for Observing Greek Elections (AMFOGE)-. Una

Achilleas MITSOS y Elias MOSSIALOS (eds.), Contemporary Greece and Europe, Ashgate, Aldershot, 2000, pp. 359372; Dimitrios KAVAKAS, "Greece», en Ian MANNERS y Richard G. WHITMAN (eds.), The Foreign Policies of European Union Member States, Manchester, Manchester University Press, 2000, pp. 144-161; Spyros ECONOMIDES, «The Europeanization of Greek Foreign Policy», West European Politics, 28/2 (2005), pp. 471-491; Dimitrios TRIANTAPHYLLOU, "The Priorities of Greek Foreign Policy Today», Southeast European and Black Sea Studies, 5/3 (2005), pp. 327-346; Sotiris RIZAS, «Atlanticism and Europeanism in Greek foreign and security policy in the 1970s", Southeast European and Black Sea Studies, 8/1 (2008), pp. 51-66. Christos KASSIMERIS, Greece and the American Embrace: Greek Foreign Policy Towards Turkey, the US and the Western Alliance, Londres/Nueva York, I. B. Tauris Publishers, 2010; Charalambos TSARDANIDIS y Stelio STAVRIDIS, «Greece...", op. cit.

${ }^{11}$ Achilleas MITSOS y Elias MOSSIALOS (eds.), Contemporary Greece and Europe, Aldershot, Ashgate, 2000; Dimitris KERIDIS y Dimitrios TRIANTAPHYLLOU (eds.), Greek-Turkish Relations in the Era of Globalization, Herndon, VA, Brassey's, 2001; Christos ROZAKIS, "La position internationale de la Grèce», Pôle Sud, no 18 (2003), pp. 101112; Heinz-Jürgen AXT, «Relations with Turkey and Their Impact on the European Union», Southeast European and Black Sea Studies, 5/3 (2005), pp. 365-378; Spyros ECONOMIDES, «The Europeanization...», op. cit.; James KERLINDSAY, Crisis and Conciliation: A Year of Rapprochement Between Greece and Turkey, Londres, I. B. Tauris, 2007; Ziya ÖNIŞ y Şuhnaz YILMAZ, "Greek-Turkish Rapprochement: Rhetoric or Reality?», Political Science Quarterly, vol. 123, 1 (2008), pp. 123-149; Angelos SEPOS, The Europeanization of Cyprus: Polity, Policies and Politics, Basingstoke, Palgrave Macmillan, 2008; Panayotis J. TSAKONAS, The Incomplete Breakthrough in Greek-Turkish Relations. Grasping Greece's Socialization Strategy, Basingstoke/Nueva York, Palgrave Macmillan, 2010; Nora Fisher ONAR y Othon ANASTASAKIS, «Introduction. Sustaining Engagement? On Symmetries and Asymmetries in Greek-Turkish Relations», Southeast European and Black Sea Studies, 13/3 (2013), pp. 401-406; Dimitrios GKINTIDIS, «Rephrasing Nationalism: Elite Representations of Greek-Turkish Relations in a Greek Border Region», Southeast European and Black Sea Studies, 13/3 (2013), pp. 455-468.

${ }^{12}$ Pese a no ocuparnos de la violencia previa al inicio estricto de la guerra civil, especial mención merece el precedente vivido en diciembre de 1944, con un inestable Ejecutivo dirigido por Papandreu y un contexto de desconfianza generalizada que dificultaba el desarme de las milicias comunistas, dramáticamente enfretadas aquel mes con el ejército británico. Cf. Alan J. FOSTER, «The Politicians, Public Opinion and the Press: The Storm over British Military Intervention in Greece in December 1944», Journal of Contemporary History, 19 (1984), pp. 453-494; Amikam NACHMANI, "Civil War and Foreign Intervention in Greece: 1946-49", Journal of Contemporary History, vol. 25, no 4 (Oct. 1990), pp. 489-522; Thanasis D. SFIKAS, «'The People at the Top Can Do These Things, Which Others Can't Do': Winston Churchill and the Greeks, 1940-45», Journal of Contemporary History, 26/2 (1991), pp. 307-332; Haris VLAVIANOS, Greece, 1941-49: From Resistance to Civil War: The Strategy of the Greek Communist Party, Londres, Macmillan, 1992; Mark MAZOWER, Inside Hitler's Greece: The Experience of Occupation, 1941-44, New Haven, Yale University Press, 1993; David H. CLOSE (ed.), The Greek Civil War, 19451950, Nueva York, Routledge, Chapman and Hall, 1993; David H. CLOSE, The Origins of the Greek Civil War, Nueva

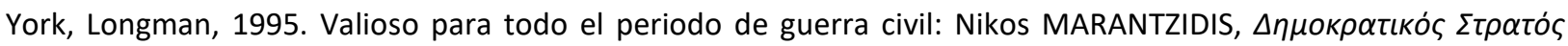

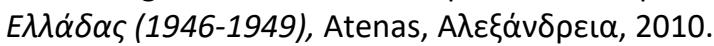

HISPANIA NOVA., 15 (2017) -págs. 217-242 DOI: https://doi.org/10.20318/hn.2017.3487 
agrupación de partidos de ideología conservadora (Inomeni Parataxis Ethnikophronon), dominada por el partido monárquico Laikon Komma, obtuvo una amplia victoria, en gran medida por la abstención mayoritaria de la izquierda; lo cual propició la convocatoria, justo cinco meses después, de un plebiscito que restableció la Monarquía antes de que amainase la oleada de sentimiento republicano resurgida a partir de la precitada ocupación.

Fue precisamente el regreso a Grecia del rey Jorge II, el 28 de septiembre, lo que desató una violenta oposición comunista que degeneró en guerra civil, sin que el fallecimiento del monarca y el subsiguiente ascenso al trono de su hermano Pablo I contribuyeran a resolver el conflicto medio año después. En buena medida, cabe pensar que los comunistas ponderaron con excesiva confianza sus posibilidades de victoria a causa del creciente poder que sus correligionarios de partido estaban obteniendo en buena parte de Europa -sobre todo en el Este, el resto de los Balcanes y parte del Centro, aunque empezaba a temerse su potencial desestabilizador en Italia y Francia- y pese al fracaso electoral que habían cosechado en las elecciones parlamentarias del 25 de noviembre de 1945 en la Austria ocupada por las potencias vencedoras.

Quizá por ello desestimaron el consejo de losif Stalin de no recurrir a la estrategia de la guerra. A juicio del líder soviético, ello forzaba, como mínimo, a la permanencia de las tropas británicas en suelo griego ${ }^{13}$, existía el riesgo de internacionalizar el conflicto, así como de propagarlo a otras zonas balcánicas, y no era previsible un triunfo comunista. Una apreciación acorde con la negativa del dirigente ruso a involucrarse de manera directa en los problemas internos de $\mathrm{Grecia}^{14}$, comprendida entonces dentro del marco de intereses británico, como se demostró en el «Acuerdo sobre porcentajes» (Percentages Agreement) que Winston Churchill ofreció al líder soviético en octubre de $1944^{15}$. En efecto, antes de iniciarse la guerra civil griega, las diplomacias soviética y británica habían abordado en varias ocasiones la distribución de sus respectivos poderes en los Balcanes. Según se dio a conocer en el sexto volumen de memorias del primer ministro británico -Triumph and Tragedy-, publicado poco después de la muerte de Stalin, en 1953, el Reino Unido aspiraba a ejercer en Grecia tras la Segunda Guerra Mundial una supremacía del 90 \% (el $10 \%$ restante sería para Rusia). Aunque también hoy se conoce la disposición soviética favorable a la suscripción de un pacto de asistencia mutua con Grecia, si las circunstancias hubieran sido otras, o, en todo caso, al establecimiento aquí de un triple acuerdo con el Reino Unido semejante al diseñado para Irán ${ }^{16}$.

\footnotetext{
${ }^{13}$ De no haberse desatado la violencia, su salida estaba prevista para después de las elecciones de marzo, tal como atestiguan las Actas de la Cámara de los Comunes tanto de 1946 como de los años posteriores. Sin duda, este fue un tema recurrente en los debates británicos sobre política exterior. Sobre este asunto, cf. asimismo: John SAKKAS, Britain and the Greek Civil War, 1944-1949: British Imperialism, Public Opinion and the Coming of the Cold War, Mainz, Franz Philipp Rutzen, 2013.

${ }^{14}$ En opinión de Tony Judt, «Stalin no tenía ningún interés de enzarzarse en una disputa con Occidente por causa de Grecia, un asunto para él secundario» (Posguerra. Una historia de Europa desde 1945, Madrid, Taurus, 2013). Por su parte, también Haris Vlavianos advierte sobre la independencia de Moscú seguida por el líder comunista griego Zachariadis (Greece..., op. cit.).

15 Panos TSAKALOYANNIS, «The Moscow Puzzle», Journal of Contemporary History, vol. 21, no 1 (1986), pp. 37-55 (p. 39).

${ }^{16}$ Geoffrey ROBERTS, "Moscow's Cold War on the Periphery: Soviet Policy in Greece, Iran, and Turkey, 1943-8», Journal of Contemporary History, vol. 46, no 1 (2011), pp. 58-81 (p. 60).
} 
Desde 1945, Rusia había firmado ya tratados de amistad con varios países de su área de influencia, como Yugoslavia y Polonia (1945), al igual que se habían establecido numerosos acuerdos entre las naciones de la Europa Centro-Oriental, sin la participación de Rusia: Yugoslavia, uno de los países que más contribuyó al fortalecimiento de la guerrilla comunista griega, pactó acuerdos, por ejemplo, con Polonia, Checoslovaquia y Albania en $1946^{17}$, lo cual tuvo su relevancia en el desarrollo de la nueva política internacional de los Estados en el inicio de la posguerra. Ello sin restar protagonismo a la retracción británica en el exterior por razones económicas. En compensación, Estados Unidos decidió intervenir en el conflicto griego a partir de marzo de 1947, poco después de que el Gobierno laborista del Reino Unido reconociera su incapacidad para solucionar aquella situación junto al depauperado Estado griego.

En términos generales, el año 1947 marcó un hito determinante tanto para el futuro de Grecia y de Europa -ambos aún demasiado inciertos - como para la conformación del nuevo orden mundial. Así, a la expansión del área de influencia soviética que propiciaban las circunstancias anteriores se le interpuso la nueva política exterior de Estados Unidos que, como se demuestra a partir de algunos documentos diplomáticos, concibió la situación de Grecia, a inicios de aquel año, como una cuestión de seguridad interna ${ }^{18}$. Un cambio de rumbo en la diplomacia estadounidense que conllevó la inmediata aprobación de la Doctrina Truman en el mes de marzo y la subsiguiente prestación de una elevada ayuda, primero, a Grecia y Turquía ${ }^{19}$ y, después, a toda Europa, cuando, el 5 de junio, el secretario de Estado norteamericano George Marshall anunció en la Universidad de Harvard su plan de asistencia para este continente (conocido en lo sucesivo como Plan Marshall).

La intranquilidad que esta acción suscitó en el Gobierno soviético, molesto ya con la omnipresencia estadounidense ${ }^{20}$, tuvo asimismo su respuesta. En septiembre, el comunismo soviético y el europeo dieron por primera vez unanimidad a su voz crítica contra las primeras medidas de la Doctrina Truman durante su encuentro internacional en Szklarska Poreba (Polonia), del que surgió finalmente la Kominform como ente coordinador de los movimientos comunistas, oficial desde el 5 de octubre. Qué duda cabe de que, a partir de esta reunión, se intensificó el apoyo al comunismo griego. Si bien esto último tuvo un carácter temporal, en cierta medida por las divisiones a que dio lugar en el entorno comunista la disposición de ciertos países como Yugoslavia y Bulgaria a establecer una federación balcánica que comprendiese también los territorios dominados por la guerrilla comunista griega $^{21}$. La enérgica intervención estadounidense en el conflicto heleno, la salida de Yugoslavia de la Kominform, el 28 de junio de 1948, y el reconocimiento soviético de la fortaleza de sus rivales ${ }^{22}$ actuó

\footnotetext{
${ }^{17}$ Ana Isabel SANZ YAGÜE, "Cronología 1945-1957», en Salvador RUS RUFINO y Ana Isabel SANZ YAGÜE, Europa. Entre la incertidumbre y la esperanza, Madrid, Tecnos, 2016, p. 99 y ss.

${ }^{18}$ Sobre la ubicación del conflicto interno griego en el marco global de la Guerra Fría, merece destacarse el Memorándum de Joseph M. Jones a Loy Henderson, del 28 de febrero de 1947. Disponible en: http://www.cvce.eu

19 Cf. el discurso pronunciado por el presidente Harry Truman el 12 de marzo de 1947. En: http://millercenter.org/president/speeches

${ }^{20}$ Geoffrey ROBERTS, «Moscow's...», op. cit., p. 65.

${ }^{21}$ Ibídem, p. 64.

${ }^{22}$ El diario del búlgaro Georgi Dimitrov registra la valoración de Stalin en torno al problema griego en los primeros meses de 1948: «Recently I started to doubt that the partisans could win [...] The Americans and the English have a very strong interest in the Mediterranean. They would like to have their bases in Greece. They would use all
} 
además como un dique de contención añadido. De hecho, en septiembre de 1949, Stalin recomendó al líder comunista griego Zachariadis sustituir la fracasada vía de las armas por una lucha política y social. $\mathrm{Y}$, al fin, la guerra terminó en octubre ${ }^{23}$, con el país exhausto y dependiente por completo del exterior.

Este resultado, así como la ayuda estadounidense -superior a los 1200 millones de dólares desde 1946 hasta $1950^{24}$, en cualquier caso con menos posibilidades de orientarse a la reconstrucción económica del país que en otros Estados europeos ${ }^{25}$ - brindaron a Grecia la posibilidad de cimentar una estabilidad política dentro del ámbito occidental y, por tanto, fuera del bloque comunista del que formaba parte el resto de los países balcánicos. Pero con un grado de libertad bastante mermado, en el sentido de que ello le hizo depender sobremanera de sus «benefactores». Solo a partir de 1974 Grecia dejó de ser un satélite de Estados Unidos para convertirse en un aliado ${ }^{26}$. De ahí que sus Gobiernos actuaran en muchas ocasiones y durante largo tiempo contra los intereses del país, sin atender las demandas de sus conciudadanos (no es que hoy se haya salvado esta brecha ${ }^{27}$ ). El clásico dilema griego, en opinión de Van Coufoudakis, ha consistido, con una indudable reincidencia, en «tener que elegir entre, por una parte, los intereses estratégicos y los compromisos adquiridos con los aliados y, por otra, los requerimientos de su opinión pública y las aspiraciones nacionales» ${ }^{28}$.

\section{LA CIMENTACIÓN DE LA UNIDAD EUROPEA}

Cabe pensar que la guerra civil obligó a Grecia a quedar al margen de los primeros actos promovidos en favor de la unidad de Europa, pero no fue así. Ello simplemente singularizó su contribución a partir de tres características esenciales. Primero, su extraordinaria dependencia de Estados Unidos a partir de 1947 determinó, como han subrayado Thanos Veremis y Dimitris Constas, que los objetivos de la política internacional de ambos países no experimentaran nunca una disociación,

possible means to support a government that would be obedient. This is an international issue of great importance...". Ibídem, p. 65.

${ }^{23}$ Ibídem, p. 65. Conviene advertir aquí además la proximidad cronológica existente entre estos hechos y los sucesos acontecidos en julio, cuanto Tito cerró la frontera yugoslava con Grecia y, con ello, el apoyo a los combatientes comunistas griegos. Cf. Tony JUDT, Posguerra..., op. cit.

${ }^{24}$ Thanos VEREMIS y Dimitris CONSTAS, «The Beginning of the Discussion on European Union in Greece», en Walter Lipgens y Wilfried Loth (eds), Documents on the History of European Integration. Vol. 3. The struggle for European Union by political parties and pressure groups in western European countries, 1945-1950, Berlín, Walter De Gruyter, 1998, pp. 801-825 (p. 803). Para una información más detallada sobre las cantidades percibidas y su comparación con las otorgadas a otros países europeos, cf.: "Greek-Turkish aid», Survey of Current Business, vol. 30 (April 1950). Asimismo, Steliois ZACHARIOU, «Implementing the Marshall Plan in Greece: Balancing Reconstruction and Geopolitical Security», Journal of Modern Greek Studies, 27, 2 (2009), pp. 303-318.

${ }^{25}$ Evanthis HATZIVASSILIOU, Greece and the Cold War: Front Line State, 1952-1967, Londres/Nueva York, Routledge, 2006, p. 9.

${ }^{26}$ P. Nikiforos DIAMANDOUROS, Cultural Dualism and Political Change in Postauthoritarian Greece, Estudios = Working papers. № 50. Madrid: Instituto Juan March de Estudios e Investigaciones, Centro de Estudios Avanzados en Ciencias Sociales, 1994.

${ }^{27}$ Una discrepancia que, como afirman, Charalambos Tsardanidis y Stelios Stavridis, aun siendo importante por las carencias democráticas que comporta, no es exclusiva hoy de Grecia. En «Greece...», op. cit., p. 124.

${ }^{28}$ Van COUFOUDAKIS, «Greek Foreign Policy, 1945-1985: Seeking independence in an interdependent world. Problems and prospects», en Kevin FEATHERSTONE y Dimitrios K. KATSOUDAS (eds.), Political Change in Greece. Before and After the Colonels, Kent, Mackays of Chatham Ltd., 1987, pp. 230-252 (p. 231). 
incluso en buena parte del periodo posbélico ${ }^{29}$. Por otro lado, y dada su dramática situación, Grecia no pudo otorgar al proceso de integración europea la prioridad que, en aquellos años, le concedieron otros Estados, por lo que solo una minoría participó de manera verdaderamente activa en este asunto. Por último, y salvando algunas loables excepciones, la acción pro-europea tuvo un marcado carácter conservador, consecuente con la marginación a la que se vieron entonces sometidas las fuerzas de izquierdas en la vida política del país. Desde el punto de vista ideológico, los debates a este respecto carecieron de la pluralidad de perspectivas apreciadas en otros países; y además se centraron en generalidades, expuestas en alocuciones repletas de idealismo, que no fijaban objetivos precisos con respecto a la manera en que debía avanzarse en esta cuestión ${ }^{30}$.

En términos institucionales, Grecia se convirtió, el 16 de abril de 1948, en miembro fundador de la Organización Europea para la Cooperación Económica (OECE), como todos los demás países que se acogieron al Plan Marshall, y se incorporó, junto con Turquía, al Consejo de Europa el 9 de agosto de 1949, poco después de su creación en los primeros días de mayo. Sin considerar la Unión Occidental (por sus aspiraciones de alcance más restringido), ambos organismos constituyen las primeras respuestas de naturaleza económica y política con las que los Ejecutivos comenzaron a despejar las dudas suscitadas sobre su interés en la unificación del continente. Pero antes hay que reconocer justamente la movilización previa que, al finalizar la Segunda Guerra Mundial, impulsaron sectores minoritarios de la sociedad, plenamente conscientes de su ciudadanía europea, con creciente capacidad organizativa y poder mediático. La vitalidad de esta reacción, que desde la sociedad civil forzó a los Gobiernos a actuar, debe mucho, en puridad, al inicial compromiso europeísta de Winston Churchill, entonces en la oposición, y a la resonancia sin precedentes que tuvo su discurso del 19 de septiembre de 1946, pronunciado en la Universidad de Zürich. Ello dio al proceso un verdadero liderazgo y un impulso de extraordinarias consecuencias, tanto por el alcance de las reacciones suscitadas en el conjunto del continente, antes de su división en bloques incomunicados, como por la celeridad que adquirió la dinámica de conformación de agrupaciones reivindicativas de la unificación desde perspectivas muy variadas.

Tras aquel discurso, hay dos actos, casi fundacionales, a los que Grecia asiste: el congreso inaugural de la Unión Parlamentaria Europea (UPE) celebrado en Gaastad (Suiza) en 1947 y el Congreso Europeo de La Haya de 1948. Antes de finalizar 1946, el conde Richard Coudenhove-Kalergi (creador en los años veinte de la Unión Paneuropea) había empezado a sondear la disposición de los diputados de muy distintas nacionalidades a dar a su labor una dimensión europea añadida. El amplio apoyo recibido posibilitó la fundación en 1947 de la UPE, la cual empezó a organizar a inicios de julio su congreso de septiembre $^{31}$. Desde un principio, la presencia griega en puestos de responsabilidad fue aquí

\footnotetext{
${ }^{29}$ Como explica Evanthis Hatzivassiliou, la implicación de EE. UU. en Grecia durante la posguerra se incrementó de manera significativa a partir de la Guerra de Corea, en 1950. Por otra parte, interesa evocar aquí su irrefutable reflexión sobre la diferencia entre los grandes y los pequeños Estados (p. 3), la cual rememora, en algunos aspectos y salvando las distancias, la expresada por Konrad Adenauer en su discurso del 25 de septiembre de 1956 en Bruselas: cuando un Estado grande y uno pequeño se asocian, lo que para el primero es un despliegue de liderazgo, para el segundo supone una sensación de dependencia y una subordinación que acaba por reducir su potencial. VEREMIS y Dimitris CONSTAS, «The Beginning...», op. cit., p. 804; Evanthis HATZIVASSILIOU, Greece..., op. cit.; Salvador RUS RUFINO y Ana Isabel SANZ YAGÜE, Europa..., op. cit., pp. 440-441..

${ }^{30}$ Ibídem.

${ }^{31}$ Salvador RUS RUFINO y Ana Isabel SANZ YAGÜE, Europa..., op. cit.
} 
significativa: Leon Maccás - diputado del partido de Georgios Papandreu y encargado de dirigir la delegación nombrada por la Asamblea Parlamentaria griega para este evento- ejerció como presidente hasta septiembre ${ }^{32}$ y Baltazzi-Mavrocordato estuvo al frente de la comisión de prensa, con la experiencia de haber desempeñado ya una ocupación similar en sus tiempos de subsecretario de Estado $^{33}$.

Leon Maccás, el más destacado europeísta griego, contribuyó a fijar las directrices preliminares de la organización que aspiraba a asentar las bases de un futuro Parlamento único europeo. Se trataba asimismo de proporcionar una base efectiva a aquellas ideas que, también desde fuera de la UPE, se mostraban conformes con una posible federación del continente. A juicio de este político griego, la necesidad otorgaba fuerza a este avance; y la UPE debía comenzar, en su proceder, por manifestar su adhesión al Plan Marshall, apelar al apoyo de la prensa, así como de especialistas (principalmente en economía y derecho público), y, por último, establecer comisiones de estudio dedicadas a evaluar, mediante el amparo de la ONU, tres materias concretas: las cuestiones coyunturales inherentes a la «Europa occidental y mediterránea» en la que se encuadraba la UPE; las relaciones entre este marco geopolítico y la Europa oriental; más las relaciones entre el conjunto de Europa y otros continentes ${ }^{34}$.

El congreso de septiembre, celebrado entre los días 8 y 10, reunió por primera vez a más de 1500 parlamentarios, «representantes electos de la Europa libre», con cuya presencia configuraban, en palabras de Leon Maccás, la «matriz del Parlamento Europeo del mañana», en un momento en que los cimientos de su edificio debían erigirse necesariamente sobre las arenas movedizas de las difíciles condiciones mundiales de aquel tiempo, lejos aún de haberse alcanzado «la libertad del ser humano por la que se han sacrificado tantos millones de hombres y de mujeres» ${ }^{35}$. Desde su criterio, el objetivo que debían marcarse aquellos primeros parlamentarios europeos - en aquel contexto, aún no revestido de la correspondiente autoridad institucional - era sobre todo «trabajar por la paz, la seguridad y la solidaridad», así como "revalorizar el principio en sí del progreso de los hombres, esta libertad del pensamiento gracias a la cual los pueblos son responsables de su destino y sus representantes, nosotros mismos, responsables ante nuestros pueblos y nuestra conciencia» ${ }^{36}$.

Desde una oratoria singular, el político griego alentaba asimismo, en aquel encuentro, a reforzar el prestigio del parlamentarismo. Si bien no era menos necesario, en un año tan crítico como 1947, la búsqueda de seductores conjuros que contribuyeran a seguir proyectando la «idea de Europa» fuera del «dominio de la quimera» para adentrarla «en la órbita de la realidad»: «iUnamos Europa!», «iLa unión o la muerte! En este momento, la consciencia de todos los europeos clarividentes gira en torno a estas

32 En el Consejo provisional de septiembre, continuó como vicepresidente primero. Cf. http://www.cvce.eu/obj/les membres du conseil provisoire de I upe gstaad 10 septembre 1947-fr36333c4b-2d3d-42cf-9458-f3604ba52bbd.html

${ }^{33}$ http://www.cvce.eu/obj/rapport sur les travaux de la conference parlementaire europeenne gstaad 4 et 5 juillet 1947-fr-e42a9345-b514-4e3e-a1cc-9a4bda27d47e.html

${ }^{34}$ Cf. Discurso de Leon Maccás durante la sesión constitutiva de la UPE (Gstaad, 4 de julio de 1947). Disponible en: http://www.cvce.eu/obj/discours de leon Maccás gstaad 4 juillet 1947-fr-eb89fb51-ad33-49a4-b7c5dc65e88af34c.html

35 Discurso de Leon Maccás (Gstaad, 8 de septiembre de 1947). En: Salvador RUS RUFINO y Ana Isabel SANZ YAGÜE, Europa..., op. cit., pp. 220-228.

${ }^{36}$ Ibídem. 
palabras y este grito». Cabe pensar que todo su discurso iba dirigido a reconducir una vez más a los europeos a aquella dimensión que, de una manera idiosincrásica ${ }^{37}$, los comprometía con grandes ideas; no menos a cicatrizar en lo más profundo las heridas de las últimas guerras, a las que llevaba el nacionalismo reincidente. En opinión de Leon Maccás, «las guerras napoleónicas, la guerra de 1870 y las dos catástrofes mundiales del siglo XX nos las hubiéramos ahorrado si Europa hubiera tomado consciencia a tiempo de lo imperiosa que era su unidad, sin desmerecer el lujo tan valioso que constituye su diversidad ${ }^{38}{ }^{3}$.

Durante el célebre Congreso reunido en La Haya del 7 al 10 de mayo de 1948, la representación griega contó al menos con 10 políticos (ninguno de ellos del Partido Socialista de Alexandros Svolos, pese a estar invitado) ${ }^{39}, 6$ académicos, el presidente de la Cámara de Comercio e Industria de Atenas y el secretario general del Instituto Heleno de Derecho Internacional. En la medida en que la convocatoria incluía a todo tipo de individuos y a agrupaciones no necesariamente políticas, el acto tuvo aún más trascendencia que el de Gstaad, también en lo que respecta a las decisiones adoptadas, que luego trataron de exigirse a los Gobiernos. Las aportaciones griegas más sobresalientes fueron de nuevo aquí las de Leon Maccás en la comisión política dirigida por el francés Paul Ramadier.

Para el precitado político griego, ovacionado en las intervenciones más revestidas de su dilatada cultura europea, la unión constructiva y provechosa de Europa exigía ante todo una voluntad legislativa integradora ${ }^{40}$. En cuanto a si aquella comisión debía explicitar la necesidad de que el proceso unificador preservara, como requisito, la igualdad entre los Estados miembros, él era partidario de hacer esta declaración, como también lo era la representante belga Tendeloo (primera en solicitarla). Aunque debiera darse por hecho que un Estado federal o una confederación de Estados no debía dar lugar a la opresión de unas naciones sobre otras, desde su criterio la demanda expresa de igualdad entre las naciones que conformaban la familia europea, más que constituir un miedo a esa opresión, denotaba la preocupación por su dignidad ${ }^{41}$.

El mismo asunto volvió a resurgir en las discusiones del proyecto constitucional en el que trabajaba la UPE durante su segundo congreso en Interlaken (Suiza), del 1 al 4 de septiembre de aquel mismo año de 1948. Así, en el debate sobre el artículo correspondiente a los «derechos de las naciones», el conservador griego Georgios Bacopoulos insistió aquí en la necesidad de que el futuro texto recogiera con precisión el principio de «igualdad». "Los Estados miembros de la unión debían compartir los mismos derechos y obligaciones» de cara a evitar el fracaso del proyecto. Al parecer,

\footnotetext{
37 Harold RALEY, Ortega y Gasset, filósofo de la unidad europea, Madrid, Biblioteca de la Revista de Occidente, 1977, p. 195.

${ }^{38}$ Salvador RUS RUFINO y Ana Isabel SANZ YAGÜE, Europa..., op. cit., pp. 223-224.

${ }^{39}$ Como excusa, los socialistas griegos alegaron no ser miembros del Parlamento. Su postura ciertamente era proeuropea pero se limitaban a asistir a congresos organizados por sus correligionarios (Alexandra PATRIKIOU, «The Greek Delegation at The Hague Congress», en Jean-Michel GUIEU y Christophe LE DRÉAU (dirs.), Le "Congrès de I'Europe» à La Haye (1948-2008), Bruselas, P.I.E. Peter Lang, 2009, pp. 233-242). No fueron los únicos que mantuvieron las distancias frente a este evento. Algunos laboristas británicos lo tildaron de conservador, dada la responsabilidad asumida en él por Winston Churchill, y aconsejaron no asistir. Justo la posición contraria del socialista francés Léon Blum, que fue partidario de apoyarlo.

${ }^{40}$ Congress of Europe. The Hague, 7-11 May 1948/ Congrès de l'Europe. La Haye, 7-11 mai 1948, Estrasburgo, Consejo de Europa, 1999, p. 101.

${ }^{41}$ Ibídem, pp. 75-76
} 
Grecia estaba dispuesta a sacrificar parte de su soberanía estatal en aras de la deseada Unión Europea, pero siempre desde la más pura equidad ${ }^{42}$.

Una de las consecuencias inmediatas que suscitó el Congreso de La Haya, tras el regreso de la delegación a Grecia, fue la creación de la Liga Helena para la Cooperación Europea (Hellenikos Syndesmos Europaikes Sunergasias). En realidad, fue obra del liberal Agis Tambacopoulos, exministro de Justicia, que ocupó en la institución el puesto de secretario general honorario. No fue la única organización pro-europea que se constituyó en este tiempo, pero sí la más conservadora. El Movimiento Internacional para los Estados Unidos Socialistas de Europa (MSEUE) también contó con representación en Grecia y, al parecer, mantuvo cierta rivalidad con la Liga. Asimismo, el influyente Movimiento Europeo, creado en Bruselas el 25 de octubre de 1948, también dispuso de un Consejo Nacional Griego antes de finalizar el año, básicamente conformado por los mismos miembros de la Liga, lo cual no gustó demasiado a los dirigentes del Comité Internacional, que, en marzo de 1949, reclamaron una mayor representatividad ideológica, es decir, incorporar en alguna medida a la izquierda griega. Un desequilibrio que apenas se subsanó un año después con la cesión por parte de la Liga de un puesto en dicho Comité Internacional a favor del MSEUE ${ }^{43}$.

El 18 de febrero de 1952, ya miembro del Consejo de Europa, Grecia accedió a la OTAN ${ }^{44}$, después de haber firmado también, el 28 de noviembre de 1950, el Convenio Europeo para la Protección de los Derechos Humanos y de las Libertades Fundamentales, lo cual había suscitado críticas, en especial británicas. En puridad, no era aún previsible que, en esta última fecha, el pueblo heleno pudiera respetar su contenido, calificado por el político británico Edelman ante la Cámara de los Comunes como la "base moral del Oeste de Europa» ${ }^{45}$. Seguían existiendo campos de concentración y, con posterioridad, la Constitución promulgada en 1952 aún adolecía de una restricción severa en la concesión de libertades. La estabilidad política del país se consiguió en aquella misma época mediante el cambio de sistema electoral de proporcional a mayoritario ${ }^{46}$.

Por entonces, Francia, Italia, la Alemania Federal y los tres Estados del Benelux ya habían dado el paso de constituir la primera institución supranacional: la Comunidad Europea del Carbón y del Acero (CECA). En lo que respecta a Grecia, los Ejecutivos conservadores que gobernaron hasta 1963 no llegaron a afrontar reformas estructurales profundas, pero sí hubo una recuperación en términos generales y un avance en el nivel de vida de los griegos, además de lograrse una importante estabilidad monetaria ${ }^{47}$.

\footnotetext{
42 Thanos VEREMIS y Dimitris CONSTAS, «The Beginning of...», op. cit., p. 810.

${ }^{43}$ Ibídem, p. 811.

${ }^{44}$ Evanthis HATZIVASSILIOU, Greece..., op. cit.

${ }^{45}$ Cf. http://hansard.millbanksystems.com/commons/1950/nov/13/council-ofeurope\#S5CV0480P0 19501113 HOC 367

${ }^{46}$ Richard CLOGG, Historia de Grecia, Cambridge, Cambridge University Press, 1998, p. 142; John S. KOLIOPOULOS y Thanos M. VEREMIS, Modern Greece. A History Since 1821, Malden, MA, Wiley-Blackwell, 2010, p. 134-135.

${ }^{47}$ Richard CLOGG, Historia..., op. cit., pp. 142-143; John S. KOLIOPOULOS y Thanos M. VEREMIS, Modern..., op. cit., p. 127 y ss.
} 


\section{TRATADO DE ASOCIACIÓN DE 1961}

En el Congreso de La Haya de 1948, se debatió ya sobre los enormes obstáculos económicos a los que se enfrentaba la unificación de Europa. A este respecto, el político griego Georges Bacopoulos planteó la duda sobre si los países que no pudieran garantizar un equilibrio presupuestario podrían ser miembros de la Unión Económica en condiciones de igualdad y si podrían disfrutar de las facilidades que proporcionaba la unión ${ }^{48}$. Posteriormente, al comienzo de los años sesenta, la desigualdad económica entre Grecia y los países que habían constituido la Comunidad Económica Europea (CEE) y la Euratom en 1957 - los mismos que integraban la CECA - era tan abismal que hacía inviable la apertura de un proceso de integración ${ }^{49}$. Sin embargo, se logró estrechar la relación entre ambas partes con la firma en Atenas, el 9 de julio de 1961, del Tratado de Asociación de Grecia a la CEE (entraría en vigor el 1 de noviembre de 1962). Este vino a colmar la voluntad mayoritaria de incorporar a la denominada Europa libre al Estado más emblemático de cuantos caracterizaban su cultura, aferrado de nuevo a Occidente, en un tiempo en el que los vínculos comerciales y económicos de Grecia con los países del Este no eran ya en absoluto despreciables ${ }^{50}$.

Las razones de este acuerdo de asociación entre Grecia y los seis países, intermedio entre el simple trato comercial y la adhesión, fueron tanto económicas como políticas. Por una parte, adquiría vida el espíritu integrador de la segunda posguerra mundial, ya que, a través de esta asociación, se aspiraba a fortalecer y garantizar la paz en Europa. Por otra, para la CEE suponía además la primera demostración tangible de su carácter abierto ${ }^{51}$, al tiempo que calmaba la desconfianza de quienes podían ver en ella una oscura intención egoísta, acaso latente tras su admirable retórica de solidaridad ${ }^{52}$. Jean Rey incidió entonces en la «significación política» («es ya un hecho que tiende a reforzar las líneas de solidaridad política y espiritual existentes entre la Europa occidental y Grecia») ${ }^{53}$. Para esta última, el acuerdo garantizaba, en palabras del primer ministro griego Constantinos

\footnotetext{
${ }^{48}$ Cf. Congress of..., op. cit., p. 211.

49 Walter HALLSTEIN, Europäische Reden. Edición de Thomas OPPERMANN, con la colaboración de Joachim KOHLER. Stuttgart, Deutsche Verlags-Anstalt, 1979, pp. 287-290.

${ }^{50}$ Cf. Jean Rey, La conclusion de l'accord d'association avec la Grèce (1961). En: http://www.cvce.eu. En este sentido, merece la pena recordar, además, los avances diplomáticos logrados pocos años después de esta fecha entre Grecia y Bulgaria (países enfrentados en el sistema de alianzas de la Guerra Fría) y pese a la crisis que precisamente en aquel verano de 1961 dificultaba sus intentos de diálogo. En 1964, y tras una década de negociaciones, ambos países firmaron un valioso acuerdo económico, de cooperación y de restablecimiento de sus relaciones, lo que suponía un cambio sustantivo en su política exterior. Cf. Evanthis HATZIVASSILIOU, "Negotiating with the Enemy: The Normalization of Greek-Bulgarian Relations, 1960-1964», Southeast European and Black Sea Studies, 4/1 (January 2004), pp. 140-161.

${ }^{51}$ Justo un mes después, tendría que empezar además a gestionar la voluntad de adhesión tanto del Reino Unido como de Dinamarca. El 9 y 10 de agosto respectivamente, ambos países comunicaron de manera formal su decisión al entonces presidente del Consejo de Ministros Ludwig Erhard. Con ello se atestiguaba todavía más «la puissance d'attraction de la Communauté» a la que Jean Rey hizo referencia durante el proceso de asociación griego. Cf. http://www.cvce.eu

${ }^{52}$ Walter HALLSTEIN, Europäische..., op. cit., p. 287.

${ }^{53}$ Cf. Jean Rey, La conclusion..., op. cit.
} 
Karamanlis, el afianzamiento de su democracia ${ }^{54}$ y una paz interna fundamentada en la estabilidad y la prosperidad $^{55}$.

El Tratado de Asociación, consensuado después de largas negociaciones, preveía un periodo de transición de unos doce años (podría prolongarse hasta un decenio más), que conduciría primero a una unión aduanera y, con el tiempo, a la integración plena. La idea era armonizar las economías de ambas partes y desarrollar la griega para que sus habitantes incrementasen su nivel de vida. Pero respetando siempre una progresión, es decir, sin acometer cambios demasiado abruptos que pudieran llevar todo el plan al fracaso ${ }^{56}$. La apreciación de Jean Rey denota las elevadas expectativas de algunos griegos:

"Los medios económicos griegos señalan de manera unánime que la asociación con los Seis aportará con el tiempo a su país una mejora del nivel de vida, la ampliación de su mercado y una balanza de pagos más equilibrada, además de desarrollar su economía y, más concretamente, su industria ${ }^{57}$.

El acuerdo constituyó en sí un precedente innovador ${ }^{58}$. Sin reproducir los mismos términos ni el mismo nivel de detalle, esta misma fórmula volvió a aplicarse en 1963 con algunos Estados africanos, así como con Turquía. En general, los textos se fueron adaptando a la peculiaridad de cada caso, como preveía el artículo 238 del Tratado de la CEE. También España intentó asociarse un año después por segunda vez, aunque sin éxito, entre otras razones por carecer de democracia (la primera demanda se cursó en 1962$)^{59}$. La excepcionalidad griega tuvo, asimismo, mucho que ver con este último condicionante.

Grecia encarnaba los valores que regían la Europa libre. Se consideraba cuna de la democracia, así como de la civilización y de la cultura europeas, tal como subrayó el entonces presidente de la Comisión, el alemán Walter Hallstein, en su discurso correspondiente a la firma del Tratado de

\footnotetext{
${ }^{54}$ Frente a la omisión del principio democrático en los primeros tratados (Tratados de Bruselas de 1948; Estatuto del Consejo de Europa, en 1949), la incorporación explícita de aquel, ligado a valores como el respeto a los derechos humanos y el Estado de Derecho, en la legitimación de estos procesos de asociación e integración de los años sesenta y setenta se ha apreciado a nivel historiográfico como una relevante incorporación progresiva (Cf. Eirini KARAMOUZI y Emma DE ANGELIS, «Enlargement and the Historical Origins of the EC's Democratic Identity, 1961-1978», en http://www.academia.edu; Eirini KARAMOUZI, Greece, the EEC and the Cold War. The Second Enlargement, Basingstoke, Palgrave Macmillan, 2014). No obstante, sin contradecir esta tesis, convendría no restar valor a la identificación que, desde la oratoria no solo política, se establece entre la integración europea y estos principios señalados, ya desde que la lucha por la liberación del yugo del totalitarismo en la II Guerra Mundial tiende sin intermisión a la unidad en los países occidentales. Cf. Salvador RUS RUFINO y Ana Isabel SANZ YAGÜE, Europa..., op. cit.

${ }^{55}$ Discours de Constantin Caramanlis à l'occasion de la signature de l'accord d'association avec la Grèce (9 juillet 1961). En: http://www.cvce.eu

Walter HALLSTEIN, Europäische..., op. cit., p. 289.

${ }^{57}$ http://www.cvce.eu/obj/jean_rey...

${ }^{58}$ El texto puede consultarse en: http://www.cvce.eu/

${ }^{59}$ Con todo, el Estado español mostró un elevado interés por conocer los pormenores de la experiencia asociativa griega. A través de su cuerpo diplomático, estuvo siempre al corriente de las enormes dificultades que comportaba su aplicación práctica, así como de las opiniones y de los estudios que, cada cierto tiempo, se publicaban al respecto. Sobre ello, cf. Matilde MORCILLO ROSILLO, "Las relaciones entre Grecia y la Comunidad Económica Europea cuatro años después de su asociación (1962-1966)», en Cincuentenario de la Declaración Schuman (9 de Mayo de 1950). El Impulso de la idea de Europa y el proceso de integración, Valladolid, CEHRI, 2002, pp. 189-204.
} 
Asociación - para sorpresa de muchos pronunciado en griego-. Si bien a menudo era una representación muy pretérita, y más simbólica que real («democracia lisiada», como bien se ha dicho) ${ }^{60}$. El 21 de abril de 1967, un golpe de Estado sumió al país durante siete años en una etapa dictatorial -el denominado régimen de los coroneles, condenado por el Parlamento Europeo (o Asamblea Parlamentaria) el 2 de junio ${ }^{61}$, en una acción que no fue realmente unánime a nivel comunitario ${ }^{62}-$. Un serio revés contra el que se unieron todos los partidos griegos sin excepción y que, por coherencia con los valores democráticos, conllevó la expulsión de Grecia del Consejo de Europa y la interrupción del Tratado de Asociación suscrito con la CEE, aunque en la práctica este siguió teniendo una vigencia parcial, más bien con respecto a la aplicación del calendario previsto para la unión aduanera ${ }^{63}$.

\section{EL IRREVERSIBLE CAMINO HACIA LA ADHESIÓN PLENA}

El régimen de los coroneles se desmoronó en el verano de 1974, formalmente desde el interior de la propia esfera militar. La torpeza de sus dirigentes había provocado la invasión turca del norte de Chipre y una delicada situación prebélica que, en un principio, se puso en manos de Constantinos Karamanlis, voluntariamente exiliado en Francia desde 1963. El 24 de julio de 1974, juró de nuevo el cargo de primer ministro para liderar una rápida transición hacia una democracia pluralista que tuvo sus primeras elecciones en el mes de noviembre y gestos relevantes como la legalización del Partido Comunista. El resultado electoral aprobó la gestión de Karamanlis, que obtuvo una amplia victoria con el partido Nueva Democracia (Néa Dimokratía). A pesar de que el régimen de los coroneles había abolido la monarquía el 1 de junio de 1973, un mes después de los comicios hubo un plebiscito al respecto con el resultado favorable a la instauración de una tercera república ${ }^{64}$.

El primer ministro no tardó en impulsar el ingreso de Grecia en las Comunidades Europeas, ante una ciudadanía, en un principio, escéptica y temerosa de los efectos económicos, y en un contexto político dividido, por cuanto una parte de la izquierda se manifestó en contra - tanto el sector comunista prosoviético como el PASOK (Panellinio Sosialistiko Kinima o Partido Socialista Panhelénico) de Andreas Papandreu que, para haberse fundado tras la caída de la dictadura, logró obtener ya casi el $14 \%$ de los votos en las elecciones de $1974^{65}$ - . La demanda se hizo oficial el 12 de junio de 1975, dos años y medio después de la primera ampliación en la que habían accedido el Reino Unido, Irlanda y

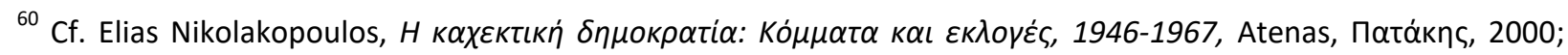

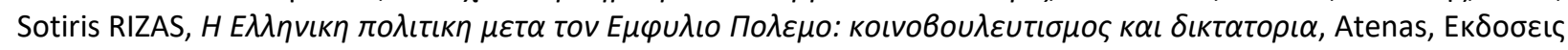

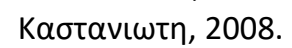

${ }^{61}$ http://www.cvce.eu/obj/resolution_du_parlement_europeen_sur_I_association_entre_la_cee_et_la_grece_2_j uin_1967-fr-74920e52-dee1-406e-8301-1a7b80873897.html

62 Eirini Karamouzi y Emma de Angelis, «Enlargement...», op. cit.

63 Ibídem. Asimismo, cf.

http://www.cvce.eu/obj/la grece_amoureuse de I europe dans la vie francaise 23 mai 1977-fr-c376b8914f3e-45a0-a8e4-d39bb576325d.html . Asimismo, Matilde MORCILLO ROSILLO, "Las relaciones...», op. cit;

${ }^{64}$ Takis S. PAPAS, Making Party Democracy in Greece, Hampshire, Macmillan, 1998; Kevin FEATHERSTONE (ed.), Politics and Policy in Greece. The Challenge of Modernisation, Londres/Nueva York, Routledge, 2006.

65 Richard CLOGG, Historia..., op. cit., p. 163; Yannis PAPADOPOULOS, «De l'opposition au gouvernement: l'évolution idéologique du PASOK», Revue française de science politique, 40 année, no 1 (1990), pp. 98-124 (p. 106)

HISPANIA NOVA., 15 (2017) -págs. 217-242

DOI: https://doi.org/10.20318/hn.2017.3487 
Dinamarca. Las negociaciones, iniciadas el 27 de julio de 1976, se preveían necesariamente complicadas, de nuevo por la clara situación de desigualdad entre las partes, pero la vigencia jurídica del Tratado de Asociación suponía ya disponer de un trabajo previo muy significativo en el que, si bien no se había avanzado en la armonización de las políticas agrarias, al parecer se habían respetado los tiempos previstos para la unión aduanera que, de no haber cambios, podría alcanzarse en $1984^{66}$.

Estados Unidos continuaba siendo el primer inversor extranjero en Grecia, pero las relaciones se habían tensado desde 1974, a partir del conflicto con Turquía sobre Chipre; y el rechazo de la opinión pública griega al gigante americano fue in crescendo, más aún cuando este firmó una nueva ayuda al Estado turco en abril de $1976^{67}$. Por otra parte, la entonces Europa de los Nueve no contemplaba problemas insalvables de cara a aceptar este nuevo ingreso. Entre otros problemas, la agricultura griega sufría un claro retraso estructural y había monopolios en el país que eran incompatibles con la libre concurrencia amparada por el Tratado de Roma. Pero, como solía destacar la prensa, también era un territorio con valiosos recursos mineros aún sin explotar, las investigaciones recientes advertían sobre la presencia de yacimientos petrolíferos y, sin lugar a dudas, disponía de una gran flota mercante. Su posición la convertía asimismo en un puente capaz de unir a los Estados comunitarios con África y Oriente Medio, especialmente allí donde la presencia de la inversión griega era significativa. Las aspiraciones griegas no variaban con respecto al anterior proceso de asociación. Junto a la necesidad económica de acrecentar su desarrollo, existía la razón política de consolidar su democracia ${ }^{68}$.

En principio, no se concibieron razones de peso para no establecer el mismo periodo de transición pautado para el anterior proceso de ampliación. Algunos datos atestiguaban que, entre 1962 y 1977, Grecia había aumentado su Producto Nacional Bruto, su producción industrial y su productividad por encima de la media de los Nueve. $Y$ el ingreso medio por habitante era similar al de Irlanda ${ }^{69}$. Aunque su crecimiento disminuyó en la segunda mitad de los setenta, seguía presentando unas tasas anuales del 3-4 \%, tras haber alcanzado incluso el 6-7\% en los años previos. Es decir, valores elevados en comparación con los de la Europa occidental ${ }^{70}$. Por consiguiente, la integración de Grecia se firmó en Atenas el 28 de mayo de 1979, en el emblemático Zappeion. Constatinos Karamanlis continuaba siendo primer ministro; cargo que reemplazó por la presidencia de la república en mayo de 1980. La entrada en vigor del Tratado de Adhesión se hizo efectiva el 1 de enero de 1981. Un año en que el Gobierno griego dejó de ser conservador para dar paso a una década dominada, en términos políticos, por el PASOK, en cuyo programa de partida figuraba incluso la intención de convocar un referéndum para decidir sobre la posible salida griega de la CEE.

\footnotetext{
${ }^{66}$ Cf. http://www.cvce.eu/obj/la grece amoureuse de I europe dans la vie francaise 23 mai 1977-frc376b891-4f3e-45a0-a8e4-d39bb576325d.html

${ }^{67}$ cf.: Theodore A. COULOUMBIS, The United States, Greece and Turkey. The Troubled Triangle, New York, Praeger, 1983; "Greek Foreign Policy: Debates and Priorities», en Theodore A. Couloumbis, Theodore Kariotis y Fotini Bellou (eds.), Greece in the Twentieth Century, London, Frank Cass, 2003, pp. 31-41.
}

${ }^{68} \mathrm{Cf}$. http://www.cvce.eu/obj/quand la grece frappe a la porte dans 30 jours d europe novembre 1976-frdb31cba7-9074-4151-bf51-800e1257bf00.html ; así como las declaraciones del gobernador del Banco de Grecia Xenophon Zolotas en el periódico francés Le Nouveau Journal, el 5 de marzo de 1974. Disponible asimismo en: http://www.cvce.eu

${ }^{69}$ Este tipo de datos se subrayaban, por ejemplo, en el periódico francés Le Monde, el 15 de septiembre de 1978, en un análisis sobre el impacto económico de la adhesión griega. Disponible en: http://www.cvce.eu

${ }^{70}$ Sarantis E. G. LOLOS, «The role...», op. cit., p. 72. 
Con todo, la acción no se armonizó con la retórica, por cuanto ni el socialismo griego llevó a la práctica su alto grado de rechazo inicial a formar parte de las Comunidades Europeas ni los conservadores fueron tan proclives a acometer los cambios que exigía desde el primer momento el nuevo estatus del país. De hecho, el PASOK y el propio Andreas Papandreu fueron moderando su resistencia de partida a este proceso, hasta el punto de considerar la integración como algo necesario para la economía del país incluso antes de finalizar la legislatura, como se aprecia en el Congreso de este partido de $1984^{71}$. Un reconocimiento que ganó en solidez cuando también este se fue imponiendo entre la población más disconforme, especialmente en las áreas rurales. Aquí, el cambio de parecer se hizo muy notorio cuando la percepción de generosos fondos procedentes de la Política Agraria Común -vinculada, eso sí, a una reestructuración- facilitó el progreso económico ${ }^{72}$.

\section{LA «PRETENDIDA» EUROPEIZACIÓN GRIEGA Y SUS FASES}

La primera década abierta a un proceso de europeización en el país heleno, a contar desde 1975 -año inicial de este proceso-, constituye solo un tiempo básicamente transicional o «de incorporación» finalizado en 1985 no solo porque así lo indicara el Acta de Acceso. Después de este último año, se abrió una etapa de "consolidación» o "afianzamiento ${ }^{73}$, en la que la resistencia griega a acometer las obligaciones que requería su compromiso de convergencia con la Europa comunitaria cedió protagonismo a una actitud distinta que valoraba esta occidentalización del país como una vía de modernización necesaria y razonable, desde la que fue cobrando forma - de manera más clara a partir de los años noventa- un tipo de "europeización pretendida», similar a la que han experimentado también otros países, como España, Portugal o los Estados del Centro y Este de Europa incorporados más recientemente ${ }^{74}$.

Este es el esquema trazado por Panayiotis C. loakimidis, quien da nombre al citado modelo de europeización (intended Europeanization), con el que se presente denotar una intención favorable por parte de los actores políticos nacionales a la hora de "transferir» al sistema político del país la lógica, las dinámicas, los rasgos organizativos y, en definitiva, el patrón de gobernanza asociado a la integración europea. Como se ha dicho antes, gracias a la relación establecida aquí entre la política comunitaria y las ideas de progreso, modernización y desarrollo económico ${ }^{75}$. Más aún, hasta hace pocos años, las

\footnotetext{
${ }^{71}$ Richard CLOGG, Historia..., op. cit., p. 178.

72 Dimitris GOUSSIOS, «The European and local context of Greek family farming», Sociologia Ruralis, vol. 35, no 3-4 (1995), pp. 322-334; Leonidas LOULOUDIS y Napoleon MARAVEYAS, «Farmers and agricultural policy in Greece since the accession to the European Union)», Sociologia Ruralis, vol. 37, no 2 (1997), pp. 270-286; Akis KALAITZIDIS, Europe's Greece. A Giant in the Making, Basingstoke, Palgrave Macmillan, 2010, p. 75.

73 Los términos entrecomillados pertenecen a Nikiforos Diamandouros (Cultural Dualism..., op. cit.). Sobre periodización en esta materia, cf. asimismo: Panayiotis C. IOAKIMIDIS, «Contradictions...», op. cit.

${ }^{74}$ Panayiotis C. IOAKIMIDIS «The Europeanization of Greece: An Overall Assessment», en Kevin Featherstone y Georges Kazamias (eds.), Europeanization and the Southern Periphery, London, Frank Cass, 2001, pp. 73-94 (p. 75).

${ }^{75}$ Panayiotis C. IOAKIMIDIS, "The Europeanization...», op. cit., pp. 74-75. Cf. asimismo sobre esta materia: Jeanne HERSANT «Contourner les normes européennes grâce... aux instruments européens. L'impératif de sécurité nationale ou les résistances à l'intégration européenne de la Grèce», Revue internationale de politique comparée, vol. 15, no 4 (2008), pp. 639-652 (pp. 640-41), Vivien A. SCHMIDT, «Europeanization of National Democracies: The Differential Impact on Simple and Compound Polities», Politique européenne, no 13 (printemps 2004), pp. 115142.
}

HISPANIA NOVA., 15 (2017) -págs. 217-242 DOI: https://doi.org/10.20318/hn.2017.3487 
referencias al marco supranacional se han llegado incluso a exponer como fuente de legitimación de cara a instaurar cambios dentro del ámbito estatal ${ }^{76}$. Particularidades todas ellas que no se han percibido en otros Estados donde la respuesta a la realidad supranacional europea ha sido más espontánea que consciente (responsive Europeanization), algo así como una especie de "ósmosis interactiva», que, a su vez, ha conllevado una menor repercusión interna ${ }^{77}$.

En efecto, la europeización griega ha supuesto y supone un gran impacto nacional a todos los niveles ${ }^{78}$. Sobre todo, desde 1985 . Porque con anterioridad resultaba muy ambigua y supeditada, desde una perspectiva interna, a la inercia de unos acontecimientos, relativamente recientes, que habían desmantelado el tejido social del país y que, en general, exponían a este a una debilitación generalizada. Una circunstancia que no solo obligó entonces a los dirigentes griegos a conformar políticas de consolidación democrática y de mejora de un retrasado estado del bienestar, sino a priorizar la reconciliación nacional, un objetivo en el que se avanzó durante los años ochenta ${ }^{79}$, aunque con despreocupación en lo que atañe a la convergencia con los países miembros de la CEE.

De hecho, en términos económicos, los Gobiernos griegos no accedieron a modificar la dirección de sus políticas, pese a que con ello contravinieran reiteradamente las normativas comunitarias y acrecentaran la divergencia con los demás Estados de la Comunidad, hasta 1985. Así, antes de esta fecha, en el programa de los conservadores prevalecieron hasta el final de su mandato las medidas macroeconómicas expansionistas, además de la decisión favorable a incrementar el papel del Estado en la economía. Todo esto en un momento en el que la debilidad estructural de esta última, junto a la fuerte inflación (próxima al $25 \%$ ), no podía ya enmascararse al final de los años setenta bajo la coartada que proporcionaba las tasas de crecimiento, aún estimables ${ }^{80}$.

Por su parte, Andreas Papandreu quiso modificar al inicio de su primera legislatura los términos en que debía desarrollarse la pertenencia de Grecia a la CEE y obtener un régimen especial en el que se rebajasen algunas de las exigencias pactadas. Y, así, en 1982, presentó ante las instituciones europeas un memorándum en el que se demandaba, entre otras cuestiones, la derogación de las medidas que obligaban a desmantelar los monopolios estatales griegos y a disminuir el control del Estado sobre ciertos sectores económicos $^{81}$. En su respuesta, las autoridades comunitarias solo accedieron a ampliar los plazos en los que Grecia debía poner en práctica las políticas de convergencia pautadas, así como a establecer una ayuda financiera mediante la aprobación, en 1985, de los Programas Mediterráneos

\footnotetext{
${ }^{76}$ No hay duda de que la gestión de la crisis ha transformado esta actitud. Christophe Bouillaud y Emmanuelle Reungoat calificaron ya los resultados de las elecciones griegas celebradas en la primavera de 2012 como «referéndum sobre Europa» (cf. su artículo: «Tous des opposants? De l'euroscepticisme aux usages de la critique de l'Europe», Politique européenne, no 43, 2004/1, pp. 9-45). Lo más significativo de aquellos comicios fue el extraordinario ascenso de Syriza, que, en junio, quedó a menos de tres puntos porcentuales del triunfador, Nueva Democracia. Un ejemplo no de "euroescepticismo», sino de "crítica al statu quo europeo procedente de partidarios de la integración», según los autores precitados, que se ha ratificado después con eventos recientes, como el referéndum del 5 de julio de 2015, con el que se cuestionó la política de austeridad europea.

${ }^{77}$ Panayiotis C. IOAKIMIDIS, «The Europeanization...», op. cit., pp. 74-75.

78 Panayiotis C. IOAKIMIDIS, "The Europeanization...», op. cit.; Loukas TSOUKALIS, "La Grèce dans I'Union européenne», Pôle Sud, № 18 (2003), pp. 91-100.

${ }^{79}$ Sarantis E. G. LOLOS, «The role...», op. cit., p. 73.

${ }^{80}$ Sarantis E. G. LOLOS, «The role...», op. cit., pp. 72-73

${ }^{81}$ Panayiotis C. IOAKIMIDIS, «Contradictions...», op. cit., p. 37.
} 
Integrados (IMPs, por sus siglas en inglés), con los que, en general, se esperaba incentivar el desarrollo de la Europa del Sur, donde se incluían ya España y Portugal ${ }^{82}$. A partir del otoño de aquel año, también apoyaron el estricto programa de estabilización que impuso el nuevo Gobierno griego durante un bienio (en junio, el PASOK había vuelto a ganar las elecciones). Se trataba de hacer frente a los turbulentos desequilibrios macroeconómicos del país desde una política coherente con los criterios comunitarios que estuvo pilotada por Costas Simitis (de convicciones mucho más europeístas que Andreas Papandreu). Sin duda, un paréntesis considerado eficaz, aunque muy breve, al que la impopularidad de las medidas y la inestabilidad política privaron de la más mínima posibilidad de continuar más allá de la primavera de $1987^{83}$.

El viraje político del PASOK, en contraste con lo que el partido había defendido antes de asumir el gobierno del país, no aportó credibilidad ni confianza a la implementación del nuevo programa, sin duda ineludible para enfrentar las serias dificultades económicas de aquel momento ${ }^{84}$. No obstante, a juicio de Sarantis Lolos, tampoco estas últimas fueron percibidas ni por un amplio sector de la clase política, ni por el resto de la sociedad, incluida la prensa ${ }^{85}$. La oposición fue generalizada y, en la arena política, donde también los conservadores se manifestaron en contra, sirvió de excusa para desarrollar una «guerra de desgaste» que favorecería a la oposición en los siguientes comicios ${ }^{86}$. A este respecto, el Ejecutivo del PASOK optó por revertir su política y eliminar el cortafuego con que se había hecho frente a la desestabilización macroeconómica. A excepción del ámbito financiero, donde se continuaron aplicando políticas liberalizadoras contra el peculiar sistema de control e intervención que tradicionalmente maniobraba el Estado, no se acometieron reformas estructurales hasta los años noventa, y las que se aplicaron sobre el sector industrial, al igual que la política laboral, por citar algunos asuntos de importancia, resultaron al parecer inapropiadas, al tiempo que se amplió más la divergencia helena con respecto a Europa. Todo ello en un contexto de inestabilidad política creciente que acabó al final de los ochenta con la hegemonía del PASOK ${ }^{87}$.

Por lo demás, la conducta griega mostró, al comienzo de los años ochenta, una inflexible resistencia en las instituciones comunitarias contra las propuestas que defendían una mayor integración de Europa. No debe olvidarse que el triunfo inicial del PASOK tuvo mucho que ver con su disposición a enarbolar la independencia del país y a anteponer los intereses nacionales en su política exterior. Así, cabe señalar la desafección griega a la iniciativa que, desde 1981, trataron de impulsar el ministro de

\footnotetext{
${ }^{82} \mathrm{Cf}$. -http://www.cvce.eu/obj/council regulation eec no 208885 concerning the integrated mediterranean programmes 23 july 1985-fr-253a6917-4ccb-41da-b0e8-f808ee381d35.html

${ }^{83}$ Sarantis E. G. LOLOS, "The role...», op. cit.; George PAGOULATOS, «The Enemy Within: Intragovernmental Politics and Organizational Failure in Greek Privatization», Public Administration, vol. 79, no 1 (2001), pp. $125-146$.

${ }^{84}$ Yannis PAPADOPOULOS, Dynamique du discours politique et conquête du pouvoir. Le cas du PASOK (Mouvement socialiste panhellénique) : 1974-1981, Berna, Peter Lang., 1989 ; «De l’opposition...», op. cit.

85 "It seemed that the Greek society (especially middle classes and self-employed), being used to living standards above their actual productive potential, was not yet ready to pay the cost of the necessary economic reforms». Sarantis E. G. LOLOS, «The role...», op. cit., p. 74.

${ }^{86}$ Ibídem, p. 74.

${ }^{87}$ Vassilis FOUSKAS, "The Left and the Crisis of the Third Hellenic Republic, 1989-97», en Donald SASSOON (ed.), Looking Left: European Socialism After the Cold War, Londres/Nueva York, I. B. Tauris Publishers, 1997, pp. 64-87; George PAGOULATOS, "The Enemy...», op. cit.; Sarantis E. G. LOLOS, «The role...», op. cit.; Richard CLOGG, Historia..., op. cit.
} 
Exteriores de la RFA Hans-Dietrich Genscher y su homólogo italiano Emilio Colombo a favor de seguir avanzando en la unión político-institucional (Iniciativa Genscher-Colombo) ${ }^{88}$. Aunque, en puridad, Grecia no fue el escollo principal que hizo fracasar este proyecto, al que la decepcionada Unión de Federalistas Europeos tildó, en enero de 1983, de "insulto al electorado europeo» ${ }^{89}$ y al que puso término, en Stuttgart, el 19 de junio de aquel año, la «Declaración solemne sobre la Unión Europea», no del todo estéril, pero sí un tanto nebulosa en opinión de Wilfried Loth ${ }^{90}$.

El último gran intento de Altiero Spinelli por federar Europa tampoco halló el sostén de los dirigentes griegos ni superó finalmente la fase de ratificación, pese a que, tras reflexionar mucho su estrategia (desde que comenzara a madurar la iniciativa, en julio de 1980, en el denominado «Club del Cocodrilo»), el eurodiputado italiano había logrado reforzar su Proyecto de Tratado de la Unión Europea -el que él mismo dirigió con un equipo ad hoc- mediante su aprobación mayoritaria en la Cámara de Estrasburgo, el 14 de febrero de 1984, y el incondicional apoyo de François Mitterrand — "Support or Instrumentalization?», se preguntaría Jean-Marie Palayret- ${ }^{91}$.

Aun a riesgo de simplificar sobremanera el contexto, la necesidad de introducir cambios de cara a avanzar en la integración europea, algo inexcusable ya a inicios de los años ochenta, trazó a menudo una divisoria entre las expectativas de los Seis países fundadores y las de los Cuatro restantes, en especial Dinamarca, Reino Unido y Grecia. En este sentido, Grecia se posicionó mayoritariamente en contra de la reforma propiamente dicha de los Tratados vigentes $y$, en consecuencia, contra la convocatoria de la Conferencia Intergubernamental de 1985, en el difícil camino hacia la elaboración y aprobación del Acta Única Europea (1986) ${ }^{92}$.

Con todo, no se trata de una resistencia absoluta. A nivel interno, en Grecia se acometieron cambios de forma inmediata allí donde más urgía armonizar los sistemas supranacional y estatal. La mera necesidad de establecer una interacción eficaz entre las partes, requirió, por ejemplo, una cierta transformación administrativa e institucional ${ }^{93}$. Por otra parte, y aun cuando la política exterior común fue una cuestión disyuntiva en la que Grecia defendió en ocasiones su derecho a adoptar una posición autónoma conforme a sus particulares intereses ${ }^{94}$, la posición helena en torno a la dualidad Este-Oste

\footnotetext{
${ }^{88}$ Las conclusiones de su labor se plasmaron en el Proyecto de Acta Europea que llegó a manos del Consejo de Ministros el 6 de noviembre de 1981 y al Parlamento el día 12. Cf. un resumen de sus objetivos en: Julio GIL PECHARROMÁN, Historia de la integración europea, Madrid, UNED, 2013.

${ }^{89} \mathrm{Cf}$.

http://www.cvce.eu/obj/resolution de I union des federalistes europeens concernant I initiative genscher c olombo bruxelles 20 janvier 1983-fr-9b30b2c5-be1c-41a1-b337-9595a5712a9f.html

90 Wilfried LOTH, "L'Allemagne et l'Italie dans le processus de construction européenne: une coopération occasionnelle? » en Piero CRAVERI y Antonio VARSORI (eds.), L'Italia nella costruzione europea. Un bilancio storico (1957-2007), Milán, Franco Angeli, 2009, pp. 455-466 (p. 465).

91 Jean-Marie PALAYRET, «François Mitterrand and the Spinelli Treaty of 1984. Support or Instrumentalization ?», en Andrew GLENCROSS and Alexander H. TRECHSEL (eds.), EU Federalism and Constitutionalism: The Legacy of Altiero Spinelli, Plymouth, Lexingon Books, 2010, pp. 103-116; Julio GIL PECHARROMÁN, Historia de..., op. cit.

92 Panayiotis C. IOAKIMIDIS, «Contradictions...», op. cit., pp. 37-38.

93 Panayiotis C. IOAKIMIDIS, «Contradictions...», op. cit., p. 38.

${ }^{94}$ Veáse su posicionamiento ante las crisis balcánicas y la desintegración de Yugoslavia durante los años noventa. La relación griega con la Serbia de Milosevic y la cuestión macedonia han merecido aquí una atención historiográfica especial. Cf., entre otras, las aportaciones de Thanos Veremis, Kostas Ifantis, Theodore A.
} 
- sin llegar a representar "un baluarte crucial del Occidente europeo», en el sentido declarado por Poulopoulos en el Congreso de La Haya de $1948^{95}$ - resultó cada vez menos ambigua. Si bien no se puede hablar de una verdadera convergencia en política exterior hasta la segunda mitad de los años noventa.

El triunfo electoral que convirtió a Costas Simitis en primer ministro en 1996 y el replanteamiento en los años sucesivos de la política exterior con respecto a los Balcanes y Turquía han permitido fijar de manera consensuada estos años como el inicio de la europeización helena propiamente dicha ${ }^{96}$; por tanto, de un fenómeno reciente en el que, según Christos Rozakis, «el eje principal de la política exterior griega» pasaría ya por la Unión Europea» ${ }^{97}$, pero con ciertos matices, ya que los cambios introducidos por las elites dirigentes no siempre ha estado consensuado con la opinión pública en temas esenciales ${ }^{98}$. Por otra parte, la crisis iniciada en 2008 ha abierto una última etapa en la que la europeización como tal comienza a verse con menos optimismo y desde una óptica más compleja y crítica, que no evita cuestionar la contingencia de una reversibilidad en este proceso ${ }^{99}$.

\section{CONTRASTES DE UNA ADAPTACIÓN ASINCRÓNICA Y TARDÍA}

Desde la atalaya del tiempo presente, puede afirmarse, en un sentido extenso, que la europeización griega - pese a tener un desarrollo tardío ${ }^{100}$ - ha conllevado cambios significativos de carácter convergente, dirigidos sobre todo a combatir la sobredimensión del aparato estatal, el modelo centralizado de gobierno, el clientelismo y la ausencia de sociedad civil. Por consiguiente, algo tan delicado y esencial como reequilibrar las relaciones entre el Estado y la sociedad ${ }^{101}$.

Couloumbis y Prodromos Yannas en: Kevin FEATHERSTONE y Kostas IFANTIS (eds.), Europe in change..., op. cit. Asimismo: Aristotle TZIAMPIRIS, Greece, European Political Cooperation and the Macedonian Question, Aldershot, Ashgate, 2000; Maximos ALIGISAKIS, "La Grèce à l'assaut des Balkans?», Confluences Méditerranée, 2001/3, no 38, pp. 51-57; Achilleas MITSOS y Elias MOSSIALOS (eds.), Contemporary Greece..., op. cit.; Takis MICHAS, Unholy Alliance: Greece and Milosevic's Serbia, College Station, Texas A \& M University Press, 2002; James KER-LINDSAY, «Engagement without Recognition: the Limits of Diplomatic Interaction with Contested States», International Affairs, 91/2 (2015), pp. 267-285.

${ }^{95}$ Cf. Congress of Europe..., p. 208.

${ }^{96}$ Cf. Charalambos TSARDANIDIS y Stelios STAVRIDIS, "Greece...», op. cit., p. 126.

97 Christos ROZAKIS, «La position...», op. cit., p. 101. En esta misma línea, cf.: Panayiotis. IOAKIMIDIS, «The Europeanisation...», op. cit.; Maximos ALIGISAKIS, "La Grèce...», op. cit.; Simone BUNSE, "The 2003 Greek Council Presidency», Mediterranean Politics, 9/2 (2004), pp. 248-257 (pp. 249-250); Spyros ECONOMIDES, «The Europeanization... ", op. cit.; Akis KALAITZIDIS, Europe's Greece..., op. cit., p. 125 y ss.;

${ }^{98}$ Sobre las notorias paradojas de la opinión pública griega, cf. Charalambos TSARDANIDIS y Stelios STAVRIDIS, "Greece...», op. cit., p. 124.

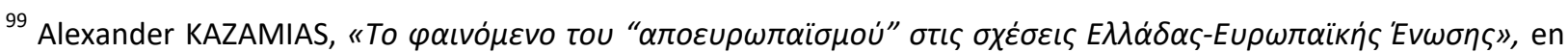
C. DIMADES (ed.), Identities in the Greek World. E-book. ESMGS, 2011, pp. 827-839. En las referencias sucesivas a este trabajo citaremos por la numeración del texto disponible en www.academia.edu

${ }^{100}$ Loukas TSOUKALIS, «La Grèce...», op. cit.

101 Panayiotis C. IOAKIMIDIS, "Contradictions...», op. cit.; Christos LYRINTZIS, "Greek civil society in the 21st century ", en Panayiotis IOAKIMIDIS (dir.), Greece in the European Union: The New Role and the New Agenda, Atenas, Ministerio de Prensa y Medios de Comunicación, 2002, pp. 90-99, Dimitri SOTIROPOULOS, Formal Weakness and Informal Strength: Civil Society in Contemporary Greece. Discussion Paper no 16 . The Hellenic

HISPANIA NOVA., 15 (2017) -págs. 217-242 DOI: https://doi.org/10.20318/hn.2017.3487 
En 1993, Dimitri Sotiropoulos calificó al Estado heleno como un «gigante con pies de barro» ${ }^{102}$. Su gran ámbito de intervención conllevaba asimismo un volumen de deuda (112\% del PNB en 1986, en torno al $100 \%$ una década después), un gasto y un déficit presupuestario excesivos. Los asalariados del sector público constituían, en 1992, el $17 \%$ de la población griega ${ }^{103}$. Un porcentaje récord al que nutría un clientelismo irrefrenable, en absoluto exclusivo del PASOK, aunque este lo dotó, en los años ochenta, de un mecanismo distinto al que antes había desarrollado Nueva Democracia, al tiempo que llevó a cabo una reorganización burocrática de gran calado estructural ${ }^{104}$.

La aceptación griega del Tratado de Maastricht supuso un punto de inflexión hacia una realidad macroeconómica distinta y una menor omnipresencia estatal, no solo mediante lo que Panayiotis loakimidis ha calificado como "la más drástica intervención de la UE en la economía helena» ${ }^{105}$. Pero quien verdaderamente despejó las dudas sobre el futuro griego y su posible pertenencia plena a la Unión Económica y Monetaria (UEM) - lograda en 2001 - fue el Gobierno del europeísta Costas Simitis a partir de 1996, al comprometerse a satisfacer los criterios de convergencia requeridos mediante la mejora de la recaudación de impuestos o la reducción del gasto y déficit públicos ${ }^{106}$.

Un esfuerzo de adaptación al que, sin embargo, sucedieron luego contextos diferentes: grosso modo, una política económica que pudo financiarse durante unos años a una tasa de interés relativamente bajo o similar a la de otros Estados - antes incluso del acceso griego a la tercera fase de la $\mathrm{UEM}^{107}$ - y un subsiguiente "atragantamiento de liquidez» como consecuencia de participar ya en un política monetaria "de talla única» ${ }^{108}$, al que después, por esta misma razón, han sucedido al menos ocho planes de austeridad, varios procesos de rescate financiero (en esencia, el de mayo de 2010 más

Observatory. The European Institute. The London School of Economics and Political Science, 2004. Disponible en: http://eprints.Ise.ac.uk/5683/1/sotiropoulos16.pdf

102 Dimitri A. SOTIROPOULOS, «A Colossus with Feet of Clay: The State in Post-Authoritarian Greece», en Harry J. PSOMIADES y Stavros B. THOMADAKIS (eds.), Greece, the New Europe and the Changing International Order, Nueva York, Pella Publishing Co., 1993, pp. 43-56.

103 Panayiotis C. IOAKIMIDIS, «The Europeanization...», op. cit., pp. 77.

${ }^{104}$ Christos LYRINTZIS, «Political Parties in Post-Junta Greece: A Case of «Bureaucratic Clientelism»?», West European Politics, vol. 7, no 2 (April 1983), pp. 99-118; Dimitri A. SOTIROPOULOS, «Bureaucrats and Politicians: A Case Study of the Determinants of Perceptions of Conflict and Patronage in the Greek Bureaucracy under PASOK Rule, 1981-1989», The British Journal of Sociology, vol. 45, no 3 (1994), pp. 349-365; George PAGOULATOS, «The Enemy...», op. cit.

${ }^{105}$ Panayiotis C. IOAKIMIDIS, «The Europeanization...», op. cit., p. 81.

${ }^{106}$ Panayiotis C. IOAKIMIDIS, «The Europeanization...», op. cit.; George PAGOULATOS, «Economic Adjustment and Financial Reform: Greece's Europeanization and the Emergence of a Stabilization State», South European Society and Politics, 5/2 (2000), pp. 191-216; "The Enemy...», op. cit. Para Alexander Kazamias, quien cuestiona que Simitis lograra, en puridad, una estabilización macroeconómica, en la intención del político griego de integrar la UEM habría pesado más el deseo de lograr un mayor volumen de fondos con los que modernizar la economía griega, que el cálculo sobre las ventajas de adoptar la moneda única. En síntesis, Kazamias definía así, ya en 1997, la actitud de Simitis: "Simitis's Europeanism is so crude and uncritical that the European Union in perceived as a solution to problems which clearly fall outside the scope of the organization's capabilities». Alexander KAZAMIAS, "The Quest for Modernization in Greek Foreign Policy and its Limitations», Mediterranean Politics, 2/2 (1997), pp.

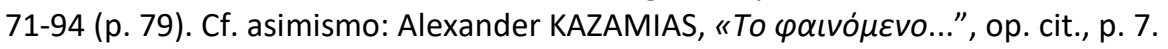

${ }^{107}$ Wolfgang STREECK, Gekaufte Zeit. Die vertagte Krise des demokratischen Kapitalismus, Berlin, Suhrkamp, 2014, p. 183.

${ }^{108}$ Manuel SANCHIS I MARCO, El fracaso..., op. cit., pp. 207-208. 
los adoptados entre julio de 2011 y febrero de 2012) y un último programa de ayuda (agosto de 2015) que ha suscitado pocas esperanzas, frente a la cruda certidumbre de que «el euro no es gratis» ${ }^{109}$. Menos aún para Grecia, a la que, según Wolfgang Streeck, la UEM solo le ha reportado hasta ahora una deuda pública muy superior a la que ya tenía en los años noventa ${ }^{110}$.

En términos sociopolíticos, la redefinición del Estado heleno en su proceso de adaptación al marco comunitario ha tenido un efecto bien distinto. Sin obviar la cuota de poder que ha transferido a las instituciones supranacionales, merece subrayarse especialmente la similar acción interna que ha supuesto dotar de autonomía a diversas instituciones sociales y económicas, así como descentralizar la administración y adoptar un patrón de gobernanza, en principio más participativo y democrático, que, a su vez, ha exigido la reforma del régimen local, así como una política de cohesión y desarrollo regional ${ }^{111}$. Todo ello después de que el proceso de europeización estableciera las bases y las condiciones favorables mediante la provisión de fondos que financiaban este tipo de cambios estructurales, en cualquier caso, acometidos con lentitud (IMPs en 1985, Paquete Delors I [1988-1992] y Paquete Delors II [1993-1999]).

En Grecia, la descentralización ha sido uno de los objetivos simbólicos del cambio ideológico y la democratización que se iniciaron con la Tercera República ${ }^{112}$. Por tanto, un deseo previo al proceso de europeización, al que este último ha fortalecido en su dificultoso desarrollo. Su puesta en marcha no solo necesitaba financiación, sino un reajuste sociopolítico profundo, un esfuerzo que exigía modificar las relaciones de poder en el interior del pueblo griego, la manera de concebir su patrón de gobierno y su cohesión interna, factores todos ellos que empezaron a cobrar impulso en los años noventa. Para Nicolas-Komnemos Hlepas, las reformas de esta década en lo que respecta al régimen local y regional (véanse la de 1994 y el "plan Kapodistrias» de 1997) "no solo han constituido un esfuerzo de modernización, sino, especialmente, tentativas de transformación del paisaje, de las proporciones y de las relaciones de fuerzas inherentes al sistema político del país» ${ }^{113}$. Aunque la renovación y la emancipación propiamente dichas de las instituciones políticas han sido, a este nivel, costosas y tardías ${ }^{114}$, al mismo tiempo que ha conllevado corrupción ${ }^{115}$.

En lo que respecta a la administración como tal, acomodada inicialmente al centralismo político del país, la europeización le ha puesto ante dos retos esenciales: su democratización y modernización. Desafíos que, sin embargo, no comenzaron a afrontarse hasta mediados de los años noventa, cuando se crearon además «una serie de autoridades administrativas independientes, limitadoras del monopolio

\footnotetext{
${ }^{109}$ Manuel SANCHIS I MARCO, El fracaso..., op. cit., p. 206.

${ }^{110}$ Wolfgang STREECK, Gekaufte Zeit..., op. cit., p. 182.

${ }^{111}$ Panayiotis C. IOAKIMIDIS, "Contradictions...», op. cit.; "The Europeanization...», op. cit.; Nicolas-Komnemos HLEPAS, "Carte administrative et pouvoir politique : les enjeux de la décentralisation en Grèce», Pôle Sud, no 18 (2003), pp. 63-78.

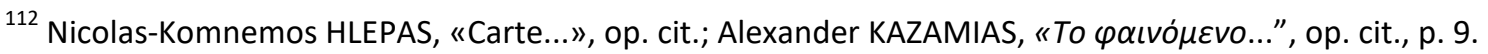

${ }^{113}$ Nicolas-Komnemos HLEPAS, «Carte...», op. cit., p. 69.

114 Nicolas-Komnemos HLEPAS, «Carte...», op. cit.; Panagiotis KARKATSOULIS, "The crisis effect on performance based budgeting», Public Administration Quarterly, vol. 34, no 4 (2010), pp. 449-478.

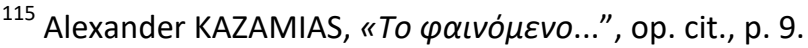


del Estado y de la centralización del poder» ${ }^{116}$. En opinión de Calliope Spanou, la europeización ha implicado también un progreso en la eficacia tanto en lo que respecta a las estructuras como a los procedimientos administrativos; ha estimulado la descentralización, la planificación y la coordinación; y, lo que no es menos importante, ha hecho consciente el retraso habido en la adaptación a las exigencias que comporta la integración europea ${ }^{117}$. Si bien los resultados suscitan aún ambigüedad, toda vez que la administración griega continúa arrastrando problemas derivados esencialmente de su pesada burocracia, la precitada corrupción y una «cultura del clientelismo» a la que no resulta fácil desterrar ${ }^{118}$.

Asimismo, cabe destacar la paulatina apertura de la política nacional a la sociedad griega. En este sentido, la UE ha estimulado con su poder coactivo la participación de asociaciones y grupos de interés en la conformación de las políticas estructurales y de desarrollo sostenidas con financiación comunitaria. Un hecho que, en definitiva, contribuye a configurar una sociedad civil, hasta ahora ausente, al tiempo que incorpora nuevos sujetos al espacio político, lo cual ha de redundar en una mejora de la calidad democrática ${ }^{119}$. Ello pese a que los cambios generen resistencias, que, a su vez, dan a la europeización griega un carácter «asincrónico». Un calificativo, este último, usado por el politólogo Panayiotis loakmidis para definir la desigual intensidad y los desajustes en el ritmo con que se ha desarrollado este proceso ${ }^{120}$.

En efecto, la europeización ha dejado a su paso perdedores, al tiempo que generaba nuevos conflictos internos, sin llegar a comprometer el proceso ${ }^{121}$. En lo que respecta a la resistencia del país a las instituciones supranacionales, conviene atender a la transformación cualitativa que ha señalado Jeanne Hersant. Así, tras quedar sepultada la intransigencia del primer Gobierno del PASOK hacia 1985 -o, si se prefiere, tras la firma del Acta Única en $1986^{122}-$, la oposición más reciente consistiría más bien en eludir normas y principios comunitarios, como la libre circulación, «en nombre de la razón de Estado - formulada en términos de "seguridad nacional" -, respaldada, si es preciso, por instrumentos europeos». Un hecho que ha de relacionarse con la singularidad del nacionalismo griego, fundamentado en la construcción de un enemigo exterior e interior que, principalmente, se encarna en

116 Calliope SPANOU, "L'administration grecque en mutation: le double défi de la démocratisation et de l'européanisation», Pôle Sud, no 18 (2003), pp. 51-62 (pp. 55-56).

117 Ibídem.

118 Panagiotis KARKATSOULIS «La Better Regulation in Grecia», en Federico BASILICA y Fiorenza BARAZZONI (eds.), Verso la Smart Regulation in Europa, Santarcangelo di Romagna (RN), Magglioli Editore, 2013, pp. $263-296$ (p. 264).

119 El segundo Plan Regional de Desarrollo (1993-1999) se desarrolló con mayor grado de implicación que el Primero (1988-1993). Y se han incrementado las asociaciones y organizaciones no gubernamentales. En lo que respecta a las financiadas por la Comisión Europea, su número se cuadruplicó entre 1996 y 1998 . Panayiotis C. IOAKIMIDIS, «The Europeanization...», op. cit., pp. 87-89.

${ }^{120}$ Panayiotis C. IOAKIMIDIS, «Contradictions...», op. cit., p. 34.

121 Panayiotis C. IOAKIMIDIS, "The Europeanization...», op. cit.; Loukas TSOUKALIS, "La Grèce...», op. cit.; Charalambos TSARDANIDIS y Stelio STAVRIDIS, "Greece...", op. cit.

122 Jeanne HERSANT «Contourner...», op. cit., p. 639 
la figura del «turco» ${ }^{123}$. Y que convierte a Grecia en el único país miembro de la UE en el que la vivencia de su entorno regional lleva incorporado un sentimiento de amenaza ${ }^{124}$.

La aguda reflexión de Nikiforos Diamandouros sobre la cultura política griega explica bien esta última singularidad, así como la lentitud con que el país acomete los cambios o, en el peor de los casos, su estancamiento ${ }^{125}$. Al margen de su valioso y rico mestizaje, Grecia sufre una ambigüedad cultural (al igual que otros Estados del Sur) en la que entran en liza dos culturas opuestas, no identificadas con partidos políticos concretos. A saber, una reformista, que se mantiene próxima a Occidente y ha acabado prevaleciendo en las últimas décadas. Y otra más atávica y pesimista, de la que se desprende aquí asimismo un síndrome de desamparo y un victimismo que, cuando cobran fuerza, causan, en lo que respecta a la política exterior, una confrontación con los Estados occidentales, a los que se atribuye un trato contaminado por el sentimiento de su superioridad y un deseo de humillación del pueblo griego $^{126}$. De este comportamiento se derivaría además una cierta querencia a buscar protección, aunque, al mismo tiempo, ello acentúe una inherente susceptibilidad a reprobarla, por el efecto deletéreo que alberga, «al conducir, por último, a la inaceptable intervención en la política interna» de actores foráneos ${ }^{127}$.

Semejante dualidad explica, en buena medida, la falta de armonía y la irregularidad con la que avanza no solo el país sino el proceso de europeización, ya de por sí complejo. Ya antes de la crisis hodierna, la interpretación recelosa del contexto impulsó a veces a la elite política griega a solicitar de las instituciones comunitarias un tutelaje insólito que ha contaminado sobremanera la interacción entre Grecia y aquellas (o el resto de países miembros), hasta el punto de generar una fuerte dosis de desacuerdo y frustración a ambas partes. A este respecto, mientras la peculiar interpretación griega del concepto de solidaridad aspiraba a asignar a la UE unas obligaciones de amparo consideradas impracticables, en las instituciones comunitarias se suscitaba el temor a contravenir los términos dialógicos propios de su política, básicamente asentada en el compromiso y la habilidad negociadora de los intereses encontrados ${ }^{128}$.

En cualquier caso, y como apreciación final, existe el esfuerzo griego por aproximarse a los parámetros de gestión y democracia propios de la UE. La asincronía de esta convergencia denota asimismo la complejidad inicial de este proceso. En su «pretendida» europeización, Grecia ha precisado acometer primero una desestructuración de gran calado contra la que se esperaban, como es lógico, no pocas resistencias. La unificación del continente europeo, aun cuando ha significado siempre un cambio revolucionario, no ha supuesto para otros Estados, véanse los Seis países fundadores de las primeras instituciones supranacionales, una transformación tan profunda en su organización interna como la que ha exigido a Grecia su adhesión a este marco comunitario. El contexto en el que se gestaron las Comunidades Europeas (segunda posguerra mundial, amenaza del totalitarismo soviético sobre Europa...) favoreció incluso emprender el reto de la integración, lo que ayudó a los Estados miembros a

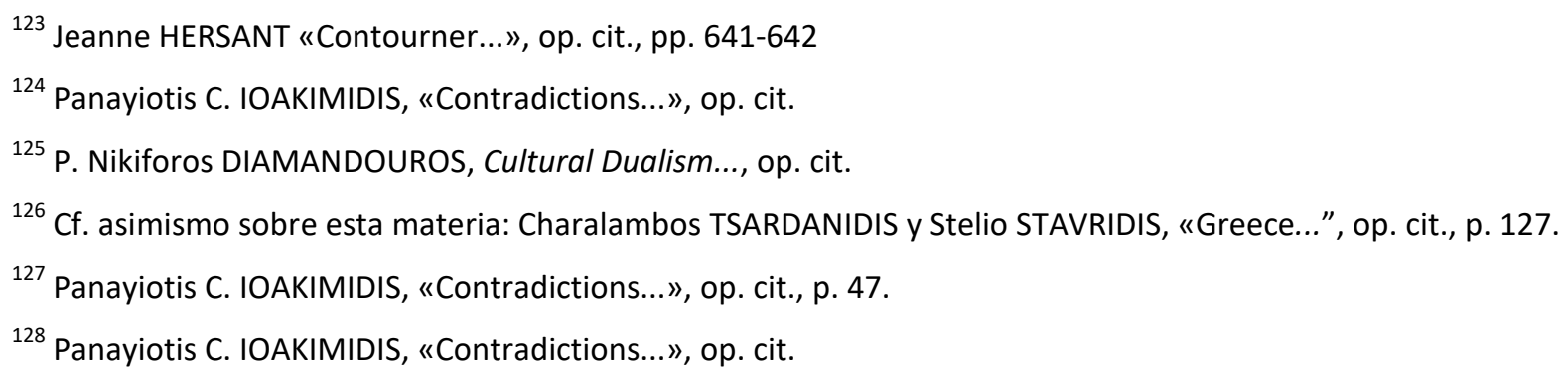


vencer su principal escollo, esto es, el nacionalismo en un sentido extenso. Inicialmente, con el modesto apoyo también de algunos europeístas griegos, como Leon Maccás, verdaderos partícipes en la promoción de la unidad del continente.

Por el contrario, y sin preterir que Grecia accedió a dichas Comunidades justo cuando su población más reivindicaba una acción independiente, tras décadas supeditada a intereses ajenos — por tanto, con una disposición interna contraria a asumir políticas de armonización demasiado abnegadas-, la convergencia con Europa ha exigido (y exige) a la sociedad griega modificar aspectos delicados que afectan directamente y de manera sistémica al modo de vida, a la ordenación sociopolítica y a las relaciones de poder. Desafíos como dotarse de una administración despolitizada o disponer de una sociedad civil, libre de los tentáculos que el sistema de partidos proyecta hacia la ciudadanía (y sobre los que se aprecian avances de forma paulatina), están aquí tardíamente relacionados con el proceso de europeización, lo que significa que el propósito griego de fortalecer su democracia con el ingreso en la Europa comunitaria ha obtenido ya resultados plausibles, a diferencia, sin embargo, de la regresión que ha experimentado su meta económica. 